\title{
Integrating Endocannabinoid Signaling and Cannabinoids into the Biology and Treatment of Posttraumatic Stress Disorder
}

\author{
Matthew N Hill*, ${ }^{\star 1}$ Patrizia Campolongo ${ }^{2}$, Rachel Yehuda ${ }^{3}$ and Sachin Patel ${ }^{\star, 4,5,6,7}$ \\ ${ }^{1}$ Departments of Cell Biology and Anatomy \& Psychiatry, Hotchkiss Brain Institute and Mathison Center for Mental Health \\ Research and Education, Cumming School of Medicine, University of Calgary, Calgary, AB, Canada; ${ }^{2}$ Department of \\ Physiology and Pharmacology, Sapienza University of Rome, Rome, Italy; ${ }^{3}$ Traumatic Stress Studies Division, Mount Sinai \\ School of Medicine, James J Peters VA Medical Center, Bronx, NY, USA; ${ }^{4}$ Department of Psychiatry and Behavioral Sciences, \\ Nashville, TN, USA; ${ }^{5}$ Department of Pharmacology, Nashville, TN, USA; ${ }^{6}$ Department of Molecular Physiology \& Biophysics, \\ Nashville, TN, USA; ${ }^{7}$ The Vanderbilt Brain Institute, Vanderbilt University Medical Center, Nashville, TN, USA
}

\begin{abstract}
Exposure to stress is an undeniable, but in most cases surmountable, part of life. However, in certain individuals, exposure to severe or cumulative stressors can lead to an array of pathological conditions including posttraumatic stress disorder (PTSD), characterized by debilitating trauma-related intrusive thoughts, avoidance behaviors, hyperarousal, as well as depressed mood and anxiety. In the context of the rapidly changing political and legal landscape surrounding use of cannabis products in the USA, there has been a surge of public and research interest in the role of cannabinoids in the regulation of stress-related biological processes and in their potential therapeutic application for stress-related psychopathology. Here we review the current state of knowledge regarding the effects of cannabis and cannabinoids in PTSD and the preclinical and clinical literature on the effects of cannabinoids and endogenous cannabinoid signaling systems in the regulation of biological processes related to the pathogenesis of PTSD. Potential therapeutic implications of the reviewed literature are also discussed. Finally, we propose that a state of endocannabinoid deficiency could represent a stress susceptibility endophenotype predisposing to the development of trauma-related psychopathology and provide biologically plausible support for the self-medication hypotheses used to explain high rates of cannabis use in patients with trauma-related disorders.

Neuropsychopharmacology Reviews (2018) 43, 80-102; doi:I0.1038/npp.2017.162; published online 23 August 2017
\end{abstract}

\section{POSTTRAUMATIC STRESS DISORDER}

Posttraumatic stress disorder (PTSD), while once characterized as a variant of an anxiety disorder, is now explicitly viewed as a separate entity and categorized as a trauma- or stressor-related disorder (APA, 2013). PTSD represents a pathological condition that emerges, sometimes after a period of incubation, following either direct or indirect exposure to a trauma. The original conceptualizations of PTSD viewed the disorder as more of a normative-type

${ }^{*}$ Correspondence: Associate Professor MN Hill, Departments of Cell Biology and Anatomy \& Psychiatry, Hotchkiss Brain Institute and Mathison Center for Mental Health Research and Education, Cumming School of Medicine, University of Calgary, 3330 Hospital Drive NW, Calgary, AB T2N4N1, Canada, Tel: +1 403 2208466, Fax: +1 4032832700 , E-mail: mnhill@ucalgary.ca or Dr S Patel, Department of Psychiatry and Behavioral Sciences, 2213 Garland Avenue, Medical Research Building IV, Rm 8425B, Nashville, TN 37232, USA, Tel: +1 615 9367768, Fax: +1 615 3221462, E-mail: sachin.patel@vanderbilt.edu

Received 21 April 2017; revised 17 July 2017; accepted 20 July 2017; accepted article preview online 26 July 2017 response that would occur following exposure to extremely stressful events, although more recent statistics indicate that it is only a proportion of individuals exposed to a trauma that actually meet diagnostic criteria for PTSD (Kilpatrick et al, 2013; Perkonigg et al, 2000). The biological mechanisms subserving the susceptibility to develop PTSD following exposure to a trauma remain elusive, although genetic factors, trauma load, and psychiatric co-morbidity are established risk factors (Almli et al, 2014; Pitman et al, 2012; Ross et al, 2017; Yehuda et al, 2015b).

In addition to trauma exposure, a diagnosis to PTSD requires presence of symptoms in four distinct clusters; intrusion, avoidance, arousal/reactivity, and negative cognitions/mood (APA, 2013; Yehuda et al, 2015b). Exposure to trauma results in generation and consolidation of trauma memory via association of environmental and interoceptive cues with the negative physical and affective consequences of trauma exposure. Although such processes facilitate avoidance of potential future harms, dysregulation of these physiological processes are thought to be central to the 
development of PTSD. Thus, current conceptualizations describe PTSD fundamentally as a disorder of learning and memory processes (Bowers and Ressler, 2015b; Ross et al, 2017). Specifically, many of the predominant theories suggest that individuals that develop PTSD either have a greater propensity to consolidate or recall emotionally laden memories, or have impairments in the ability to appropriately extinguish associations between environmental cues and the negative effects and consequences of traumatic stress exposure (Careaga et al, 2016; Milad et al, 2009; Orr et al, 2000; Wicking et al, 2016). In addition, impairments in physiological habituation, or pathological sensitization mechanisms, are thought to contribute to the delayed onset of PTSD that often occurs (Lissek and van Meurs, 2015). Such dysregulations can result in intrusive re-experiencing symptoms in the forms of flashbacks or nightmares, and development of avoidance behaviors to minimize exposure to 'triggers', which predict danger and generate negative affective states. Hyperarousal and negative cognitive/mood states can be considered consequences of persistent re-experiencing and avoidance, as well as the associated functional decline often seen in PTSD patients. Overall, PTSD can be a highly debilitating illness often co-existing with anxiety disorders and substance use disorders, making effective treatment challenging with conventional approaches such as SSRIs and cognitive-based psychotherapies.

The biological underpinnings of PTSD have been difficult to establish, although disturbances in a wide array of biological systems that could contribute to the development and maintenance of PTSD have been proposed (Horn et al, 2016; Kelmendi et al, 2016; McFarlane et al, 2017; Pitman et al, 2012). Not surprisingly, distributed cortico-limbic circuits important for salience attribution, cognitive processes, and emotion generation and modulation have been implicated in the pathophysiology of PTSD. The amygdala represents a key structure in this regard, given its importance in the processing of emotionally relevant information, consolidation and extinction of emotional memories (particularly those related to traumatic stress), generation of anxiety states, and its role in activation of the sympathetic nervous system (SNS) in the periphery (Duvarci and Pare, 2014; Janak and Tye, 2015; LeDoux, 2007). The amygdala is particularly relevant for both the recognition (often at a preconscious level) of threatening stimuli in the environment, as well as the assembly of a behavioral response to threat, such as the generation of states of vigilance (Duvarci and Pare, 2014; Janak et al, 2015; LeDoux, 2007). With respect to PTSD, the amygdala appears to be hyper-reactive, exhibiting elevated metabolic activity during periods of heightened symptom presentation and showing increased responsiveness to emotionally salient information, even stimuli unrelated to the trauma itself (Diamond and Zoladz, 2016; Hughes and Shin, 2011; Sheynin and Liberzon, 2016; Shin et al, 2006).

In addition to the amygdala, subregions of the prefrontal cortex (PFC) are also believed to be relevant to the development and maintenance of PTSD. Specifically, the ventromedial PFC (vmPFC) in humans has repeatedly been found to be hypofunctional in individuals with PTSD (Hughes and Shin, 2011; Pitman et al, 2012), particularly during processing of trauma-related information and during extinction related tasks. For example, deficient recruitment of the vmPFC during fear extinction is believed to relate to the impairments in extinction seen in PTSD, which is consistent with the established role of the vmPFC in promoting the extinction process. In fact, the reduction in vmPFC activity inversely correlates with the severity of PTSD symptoms (Shin et al, 2004), and there are consistent inverse relationships between activation of the vmPFC and amygdala, such that hyperactivity of the amygdala in PTSD is related to hypoactivity of the vmPFC (Shin et al, 2004). This coupling, both functional and structural, between the vmPFC and amygdala is known to be very important for emotional regulation, in addition to emotional memory stability, and impaired coupling of these structures is reliably found in individuals with PTSD or anxiety-related disorders (Gilmartin et al, 2014; Harris and Gordon, 2015; Kim et al, 2011; Likhtik and Paz, 2015). That being said, there are specific variants and subsets of this disease, such as those which experience a high degree of dissociation, that may represent as unique subtype of PTSD, which exhibits opposite alterations in activation of these cortico-limbic circuits (Lanius et al, 2010). As such, the proceeding discussion more specifically relates to the classic and typical presentation of PTSD, which is characterized by re-experiencing and hyperarousal.

In addition to these alterations in functional patterns of activity within cortico-limbic circuits, there are also alterations in many neuroendocrine systems in PTSD. A more indepth discussion of these findings can be found in (Daskalakis et al, 2013). Many of the initial studies of neuroendocrine function in PTSD demonstrated that, while individuals with PTSD appear to exhibit elevated levels of catecholamines and corticotropin releasing hormone (CRH), circulating levels of cortisol were quite surprisingly reduced in PTSD (Yehuda et al, 1996; Mason et al, 1986; Yehuda, 2009). Since these early studies, reduced levels of cortisol have generally been found to be a consistent and widespread finding in PTSD patients; although it is unclear whether reduced levels of glucocorticoids represent a cause or consequence of the disease, or reflect early adverse experiences impacting HPA-axis function (Daskalakis et al, 2013). There is some indication that these alterations in cortisol levels may in fact be reflective of alterations in regulatory components of the HPA-axis, such as FKBP5, a chaperone protein for the glucocorticoid receptor for which gene variants have been explicitly linked to susceptibility to PTSD (Binder et al, 2008; Klengel et al, 2013; Yehuda et al, 2009). The current data would indicate that alterations in glucocorticoid receptor sensitivity to cortisol could be associated with PTSD, such that greater receptor sensitivity could result in enhanced negative feedback and consequential reductions in circulating levels of cortisol (Binder, 2009). 
Ongoing work is attempting to further understand and characterize the nature of these HPA-axis disturbances.

These lower-than-expected levels of cortisol have also been found to associate with a disinhibition of SNS activity in PTSD, which then results in persistent and steady-state increases in catecholamine secretion (Daskalakis et al, 2013). This chronic elevation in catecholamines, in turn, is associated with many PTSD symptoms such as hyperarousal and distress (Daskalakis et al, 2013; Krystal and Neumeister, 2009). Interestingly, human imaging work has found that glucocorticoids play an important role in tempering amygdala responses to threatening cues and can sculpt functional connectivity between the amygdala and frontal cortical regions during emotional processing (Henckens $\mathrm{et} \mathrm{al}$, 2010, 2012; Joels et al, 2011). Preclinical studies have generally supported these findings, such that animal models of traumatic stress find lower levels of HPA responses to traumatic stressors are associated with greater long-term maladaptive changes (Bowens et al, 2012; Krishnan et al, 2007; Whitaker and Gilpin, 2015), and that glucocorticoids are required for normative fear extinction (Bitencourt et al, 2014; Yang et al, 2006, 2007). More so, preclinical research indicates that glucocorticoid administration in the immediate aftermath of traumatic stress exposure can restrict the development of long-term maladaptive changes from emerging (Whitaker et al, 2016; Zohar et al, 2011), which is paralleled by clinical evidence that elevating glucocorticoid levels could be ameliorative in the treatment of PTSD (Aerni et al, 2004; Yehuda et al, 2015a). As such, reduced levels of glucocorticoids, coupled to elevated levels of catecholamines, could very well be a primary contributing factor in PTSD, possibly working through impairing fear extinction processes, sensitization of the amygdala, and reduced functional coupling of the amygdala and vmPFC.

Another recent advance in the field of PTSD is the increased recognition of the role the immune system and inflammatory processes could play in the development of the disease (Michopoulos et al, 2017; Wieck et al, 2014). Elevated markers of inflammation such as C-reactive protein and proinflammatory cytokines have been identified in both the CSF and circulation of individuals with PTSD, both at rest and in response to an immune challenge (Michopoulos et al, 2017). Similarly, gene network and genome wide association studies have implicated immune-related genes in PTSD (Breen et al, 2015; Nievergelt et al, 2015; O'Donovan et al, 2011; Yehuda et al, 2009). At a functional level, it is interesting that cytokine signaling is known to promote emotional memory expression and impair fear extinction (Bi et al, 2016; Yu et al, 2017). In addition, preclinical studies have demonstrated that pro-inflammatory cytokines can facilitate glutamatergic transmission onto, and promote activation of, amygdalar pyramidal neurons (Chen et al, 2013; Engler et al, 2011; Prager et al, 2013). Similarly, in humans, inflammation and pro-inflammatory cytokines are related to enhanced activation of the amygdala in response to threatening stimuli (Inagaki et al, 2012; Swartz et al, 2017), further implicating immune dysregulation in the pathophysiology of PTSD.
Taken together, these findings indicate a prominent role of an imbalance in cortical-amygdala coupling, with hyperactivity of the amygdala and hypoactivity of the vmPFC in PTSD. In addition, PTSD is associated with reduced levels of cortisol, excess levels of catecholamines, and a state of persistent inflammation. These processes likely exist in a reciprocal feed-forward situation, where reduced levels of cortisol and elevated levels of norepinephrine and pro-inflammatory cytokines sensitize the amygdala and impair its coupling to the vmPFC, which in turn may provide additional drive on both the SNS and immune system (Muscatell et al, 2015; Tawakol et al, 2017). Because many of these biological and behavioral processes are influenced by cannabinoids and endocannabinoid (eCB) signaling, the overarching aim of this review is to provide a comprehensive summary of the current state of knowledge regarding how cannabinoids and $\mathrm{eCB}$ signaling influence these processes in PTSD, and how eCB signaling could both represent a substrate for etiology of PTSD as well as a target for the development of novel therapeutics.

\section{CANNABIS AND ENDOCANNABINOIDS}

Cannabis is the most commonly used illicit recreational drug around the world, and contains over 80 terpeno-phenol molecules, which fall under the umbrella of 'cannabinoids' (Izzo et al, 2009). These plant-derived cannabinoids are typically referred to as phytocannabinoids, the most wellknown of which is $\Delta^{9}$-tetrahydrocannabinol (THC), the primary psychoactive constituent of cannabis (Izzo et al, 2009). In addition to THC, the phytocannabinoid cannabidiol $(\mathrm{CBD})$ is potentially relevant for the effect of cannabis on PTSD. While THC is known to exert its effects through direct activation of cannabinoid receptors, the pharmacology of CBD is more enigmatic and involves interactions with a series of neurochemical systems, most notably through interactions with serotonergic and adenosine signaling (Carrier et al, 2006; Izzo et al, 2009; Rock et al, 2012).

Much of our knowledge of the eCB system has been derived from pharmacological studies investigating the mechanisms by which THC exerts its pharmacological effects. From almost three decades of research now, we have a firm understanding of the major components of the eCB system and how it works (for an in-depth discussion see the review by Marsicano and colleagues in this issue). In brief, the eCB system is a neuromodulatory lipid system, which is composed of two cannabinoid receptors, $\mathrm{CB} 1$ and $\mathrm{CB} 2$ (Matsuda et al, 1990; Munro et al, 1993), and two major endogenous ligands, $\mathrm{N}$-arachidonoyl ethanolamine (anandamide, AEA; (Devane et al, 1992)) and 2-arachidonoyl glycerol (2-AG; (Sugiura et al, 1995)). CB receptors couple to $G_{i / o}$ proteins that function to inhibit adenylyl cyclase activity, activate potassium channels, and inhibit voltagegated calcium channels (Howlett, 2002). CB1 receptors are the most abundantly expressed G-protein coupled receptor 
in the brain and are primarily localized to axon terminals. As such, activation of CB1 receptors results in a suppression of neurotransmitter release into the synapse (Katona and Freund, 2012). CB1 receptors are widely expressed on almost all neuronal types in the brain, including GABAergic, glutamatergic, serotonergic, noradrenergic, and dopaminergic terminals, but the primary effects of $\mathrm{CB} 1$ receptor activation appear to be mediated by their regulation of fast synaptic transmission and their localization to GABAergic and glutamatergic terminals (Katona and Freund, 2012). CB2 receptors are primarily located in immune cells, although there is emerging and controversial evidence of neuronal expression, and when activated, can modulate immune cell migration and cytokine release both outside and within the brain (Atwood and Mackie, 2010). There are also non-CB receptor targets of eCB molecules, including peroxisome proliferator-activated receptor and transient receptor potential vanilloid type 1 (TRPV1; (Mechoulam et al, 2014)).

AEA and 2-AG are not stored in vesicles, and appear to be synthesized on-demand from phospholipid precursors in the somatodendritic compartment of neurons, typically in response to calcium influx or activation of intracellular phospholipases. In the canonical view, AEA and 2-AG signal as retrograde transmitters, being synthesized in the postsynaptic neuron and activating $\mathrm{CB} 1$ receptors on axon terminals to modulate neurotransmitter release (Katona and Freund, 2012). The biosynthesis of AEA is complex and seems to involve multiple redundant pathways, whereas its metabolism is almost entirely mediated by the enzyme fattyacid amide hydrolase (FAAH; (Blankman and Cravatt, 2013)). The biosynthesis of 2-AG, on the other hand, is mediated by the conversion of diacylglycerol to 2-AG by the enzyme diacylglycerol lipase (DAGL), and its metabolism is primarily driven by the enzyme monoacylglycerol lipase (MAGL; (Blankman and Cravatt, 2013)).

Generally speaking, eCB signaling at the synapse leads to either transient or sustained suppression of neurotransmitter release from the axon terminal. Although both AEA and 2-AG similarly act to suppress pre-synaptic transmitter release, it has been hypothesized that these two molecules of the eCB system operate in tonic and phasic modes, respectively, thereby differentially regulating homeostatic, short-term, and long-term synaptic plasticity processes within the brain (Ahn et al, 2008; Katona and Freund, 2012). Within this conception, it is thought that AEA may represent the 'tonic' signaling molecule of the eCB system, acting to regulate basal synaptic transmission, whereas 2-AG may represent the 'phasic' signal, being released during sustained neuronal depolarization and mediating many forms of synaptic plasticity; however, exceptions to this dichotomy have also been proposed.

\section{CANNABINOIDS AND PTSD}

While the prevalence of PTSD is believed to be quite high in the general population-WHO estimates an approximate $4 \%$ lifetime prevalence of PTSD (Koenen et al, 2017)—current treatment approaches are only partially effective. Psychotherapy treatments, such as exposure therapies, seem to be limited both by logistical issues due to the regularity required, and many individuals who undergo treatment often don't have sustained recovery from symptoms (Spoont et al, 2010; Watts et al, 2014). In addition, many of the conventional pharmacotherapeutic options for the treatment of PTSD yield only modest clinical benefits (Hoskins et al, 2015). Interestingly, numerous case reports have emerged in recent years, particularly from veterans in North America and Israel, suggesting cannabis as a means to treat PTSD symptoms. Specifically, many patients with PTSD cite motives of self-medication for continued use of cannabis due to its ability to promote relaxation and sleep, and reduce anxiety symptoms and hyperarousal (Betthauser et al, 2015; Bonn-Miller et al, 2007a; Bremner et al, 1996). While rigorous studies regarding the efficacy of cannabis for PTSD are lacking, there have been a series of small studies investigating synthetic cannabinoids in the treatment of PTSD. Nabilone, which is a synthetic analog of THC, has been directly examined in PTSD. The first study of this kind was an uncontrolled open-label study, where administration of Nabilone prior to bedtime reduced nightmares in patients with PTSD, with $34 / 47$ patients exhibiting either total cessation or significant reduction in nightmare occurrence (Fraser, 2009). For several of the subjects, nightmares occurred again almost immediately following cessation of Nabilone treatment, and were again suppressed following re-initiation of the drug, suggesting that these effects were specific to cannabinoid treatment. Similarly, a retrospective chart review of inmates at a correctional facility found that Nabilone treatment was associated with a significant improvement in sleep and a reduction in nightmare severity/frequency as well as a general reduction in PTSD symptom severity (Cameron et al, 2014). Another openlabel, uncontrolled pilot study examined the impact of adding THC onto existing medications on PTSD symptom severity and found that THC consumption specifically improved sleep quality, reduced nightmares, and reduced symptoms of hyperarousal (Roitman et al, 2014). Finally, in a small, randomized, double-blind, placebo controlled crossover study, Nabilone administration again significantly reduced the severity and frequency of nightmares, and increased general well-being (Jetly et al, 2015). Taken together, these studies support potential benefit of cannabinoids in the domains of hyperarousal, sleep, and nightmares in PTSD; however, limitations due to study design and small sample sizes need to be overcome before any firm conclusions can be drawn regarding clinical efficacy of cannabinoids for the treatment of PTSD.

Potential publication bias notwithstanding, given the relative consistency in published reports, these findings beg the question as to whether cannabinoids could represent a novel treatment strategy for managing PTSD. As such, the aim of the current review is to take a step back and ask two questions. First, do cannabinoids and/or eCB signaling 
mechanisms modulate the biological processes relevant to the pathophysiology of PTSD, and is the direction of modulation consistent with a potential therapeutic benefit? And second, given that exogenous cannabinoids interact with the eCB signaling system, is there evidence that a disturbance in $\mathrm{eCB}$ function could actually be a predisposing factor in the development of PTSD? For example, could deficient eCB signaling both contribute to the development of PTSD and explain the symptom-coping motives highly cited by PTSD patients who use cannabis (Bujarski et al, 2012)?

\section{ENDOCANNABINOIDS, CANNABINOIDS, AND NEUROENDOCRINE SYSTEMS}

eCBs have been heavily implicated in modulation of the physiological and behavioral sequelae of stress exposure, particularly with respect to neuroendocrine aspects of the stress response (for a more in-depth review on this subject see Hillard et al (2016); Lutz et al (2015); Morena et al (2016b)). With respect to the HPA-axis, eCB signaling appears to be an important modulator of activation and termination of the HPA-axis function. Specifically, studies examining the effects of stress exposure on eCB levels have revealed two wellestablished patterns of effects. First, acute and repeated stress exposure reduce AEA levels in several limbic regions including the amygdala, PFC, hippocampus, and hypothalamus (Figure 1) (Bluett et al, 2014; Dubreucq et al, 2012; Gray et al, 2015; Hill et al, 2008a, 2009a, 2010c, 2013b; Jennings et al, 2016; Patel et al, 2004, 2005; Rademacher et al, 2008). This reduction in AEA signaling appears to be mediated by CRH signaling at the CRH1 receptor (Gray et al, 2015, 2016; Natividad et al, 2017). Interestingly, glucocorticoid hormones have been found to increase AEA levels within areas of the brain, such as the amygdala, in the short term (Hill et al, 2010a), a process which is thought to be involved in the normalization of reduced AEA content following exposure to stress (Morena et al, 2016b). The relationship between AEA and glucocorticoids has also been found in the periphery and in humans, whereby chronic exposure to glucocorticoids increases circulating levels of AEA in rodents (Bowles et al, 2015), and circulating levels of cortisol in humans positively correlate with circulating levels of AEA (Hill et al, 2013a). As such, these data indicate that CRH signaling decreases AEA signaling, through an increase in FAAH-mediated AEA hydrolysis, while glucocorticoid hormones seem to increase AEA signaling. In addition, suppression of AEA signaling within the amygdala has been found to correlate to the magnitude of the HPA response to stress, and in line with this, systemic, or intra-amygdala, inhibition of AEA hydrolysis has been found to dampen basal or stress-induced activation of the HPA-axis (Bedse et al, 2014; Hill et al, 2009a, 2010c; Patel et al, 2004).

The second pattern of stress-induced changes in $\mathrm{eCB}$ signaling involves a stress-induced increase in 2-AG levels, particularly within the amygdala and PFC, after acute, and
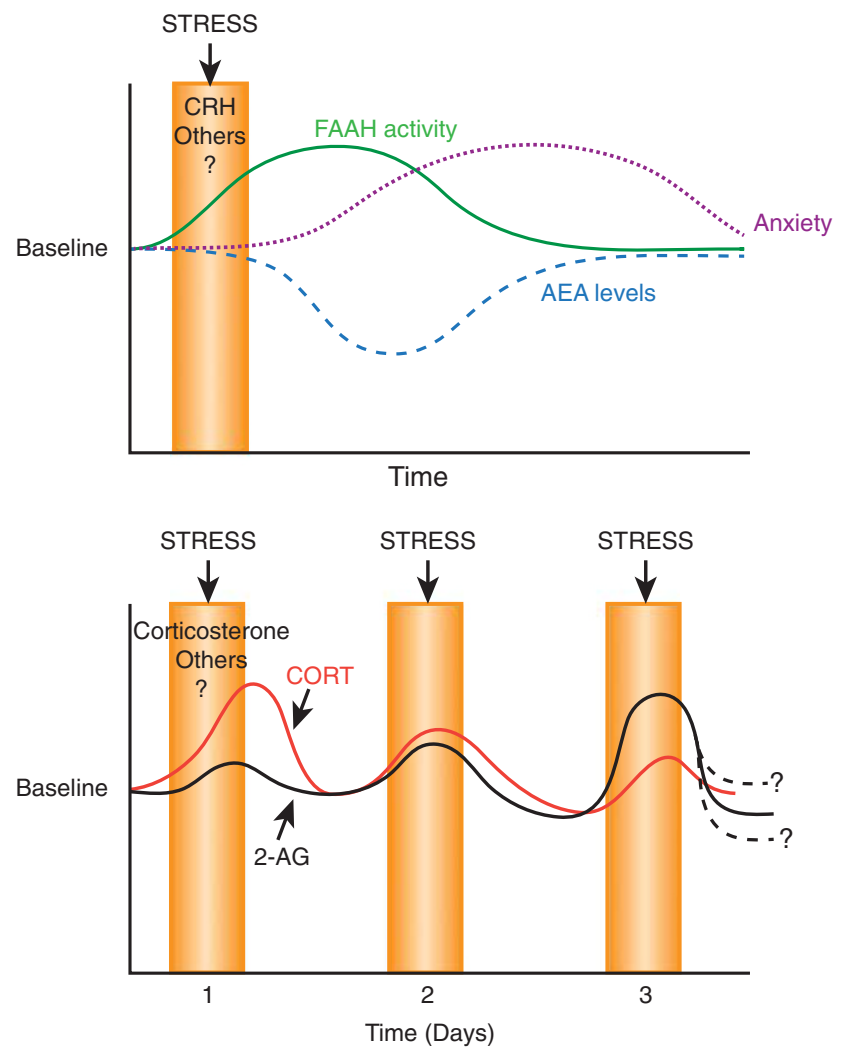

Figure 1. Effects of stress on eCBs and the proposed link to related physiological and behavioral processes. (Top) Stress exposure causes $\mathrm{CRH}$ release, which in turn increases FAAH activity to drive down AEA levels within cortico-limbic structures. This reduction in AEA plays a permissive role in the expression of stress-induced anxiety-like behaviors. Pharmacological blockade of FAAH would 'clamp' AEA at high levels and thus prevent stress-induced AEA reductions and thereby prevent stressinduced anxiety (not shown). (Bottom) Stress exposure increases 2-AG levels in the amygdala and PFC possibly driven by stress-induced corticosterone release. Upon subsequent stress exposures the 2-AG response shows sensitization via a mechanism which may involve impaired degradation (Sumislawski et al, 2011). This progressive increase in stress-induced 2-AG release in the amygdala is correlated with habituation of the HPA-axis response (red) to repeated homotypic stress exposure (Hill et al, 2010c).

especially repeated homotypic stress exposure (Figure 1) (Bluett et al, 2017; Dubreucq et al, 2012; Evanson et al, 2010; Gray et al, 2015; Hill et al, 2008a, 2010c, 2011b; Patel et al, 2004, 2005; Rademacher et al, 2008; Wang et al, 2012). These increases appear to be relatively short-lived and return to baseline in many cases within hours. The primary mechanism mediating these increases is the release of glucocorticoid hormones (see Balsevich et al, 2017). Glucocorticoids increase 2-AG release through both genomic and nongenomic mechanisms that have yet to be fully described (Di et al, 2005, 2016; Wamsteeker et al, 2010; Wang et al, 2012), and acute stress-induced increases in amygdala 2-AG positively correlate with amygdala corticosterone levels (Bedse et al, 2017). Stress-induced increases in 2-AG are important for several aspects of the stress response, however, a primary function is to contribute to glucocorticoidmediated negative feedback termination of the stress 
response as well as the development of habituation and adaptation under conditions of repeated exposure to homotypic stressors (Bluett et al, 2017; Bosch-Bouju et al, 2016; Hill et al, 2010c; Patel et al, 2004, 2005). That being said, one study has found that although pharmacological augmentation of 2-AG signaling reduced acute stressinduced peak corticosterone, it also prolonged the recovery of the HPA-axis response to stress (Roberts et al, 2014). Accordingly, disruption of this 2-AG/CB1 receptor signaling can impede termination of the stress response and impair normative adaptation to repeated stress exposure (Hill et al, 2010c, 2011b; Patel et al, 2005). Interestingly, in humans acute exposure to social stress has been found to increase circulating levels of 2-AG (Hill et al, 2009b), and a separate report found that individuals that did not mount an increase in 2-AG in response to parabolic flight stressor exhibited dramatic activation of the HPA-axis (Chouker et al, 2010), suggesting that in humans, 2-AG signaling may also relate to tapering the magnitude of the stress response.

In addition to studies describe above, it is well established that blockade of $\mathrm{CB} 1$ receptors increases stress-induced corticosterone release (Patel et al, 2004), and CB1 receptor $\mathrm{KO}$ mice exhibit higher basal, and exaggerated stressinduced, corticosterone release (Barna et al, 2004; Cota et al, 2007; Hill et al, 2011a; Roberts et al, 2014). Furthermore, direct blockade of $\mathrm{CB} 1$ receptors in the amygdala increases HPA-axis activity in and of itself (Ganon-Elazar and Akirav, 2009; Hill et al, 2009a) and blockade of CB1 receptors in the $\mathrm{mPFC}$ exaggerates restraint stress-induced corticosterone release (Hill et al, 2011b). Taken together these data suggest AEA signaling may be involved in acute negative regulation of stress-induced HPA-axis activation, while 2-AG signaling appears to regulate acute termination and long-term habituation of this system, and that the amygdala, mPFC and hypothalamus appear to be key sites of action in eCB regulation of HPAaxis function.

The effects of cannabinoids on stress-induced corticosterone release have also been well-studied in rodents. For example, THC and synthetic cannabinoids can dose dependently increase the activity of the HPA-axis, measured by increases in plasma ACTH and corticosterone levels (Johnson et al, 1978; Manzanares et al, 1999; Pertwee, 1974; Puder et al, 1982; Zuardi et al, 1984). Similar effects have been observed with synthetic cannabinoid agonists (Barna et al, 2009; Marin et al, 2003; McLaughlin et al, 2009; Patel et al, 2004; Rodriguez de Fonseca et al, 1995; Romero et al, 2002), which are likely mediated via activation of $\mathrm{CB} 1$ receptors (Romero et al, 2002), and may involve increases in serotonergic and noradrenergic activity (McLaughlin et al, 2009). Moreover, THC and synthetic cannabinoid agonists can augment stress-induced corticosterone release via a CB1-mediated mechanism (Jacobs et al, 1979; Patel et al, 2004; Sano et al, 2009). In contrast, some studies have shown that THC and synthetic cannabinoids, especially at low doses, can reduce stress-induced corticosterone release (Ganon-Elazar and Akirav, 2012; Mayer et al, 2014; Patel et al, 2004). These findings highlight a key difference between $\mathrm{eCB}$ signaling and exogenous cannabinoids in the regulation of HPA-axis function and related behavioral processes such as anxiety. Specifically, eCB augmentation approaches via FAAH inhibitors or MAGL inhibitors generally produce dose-related decreases in these parameters, whereas THC and exogenous cannabinoids produce biphasic effects with low doses mimicking eCB augmentation effects while high doses actually increase HPA-axis function and associated anxiety-related behavioral responses (Figure 2).

With respect to the SNS, fewer studies have examined the interaction of eCB signaling and the regulation of catecholamine release. $\mathrm{CB} 1$ receptors are known to be localized onto peripheral sympathetic terminals, where activation of $\mathrm{CB} 1$ with either THC or AEA can suppress the release of norepinephrine either into target tissue sites (eg, heart or lung) or into the general circulation (Ishac et al, 1996; Molderings et al, 1999; Niederhoffer et al, 2001, 2003; Vizi et al, 2001). Similarly, facilitation of eCB signaling reverses $\mathrm{CRH}$-mediated elevations in circulating catecholamines, indicating that eCB signaling acts to restrict drive onto the SNS by stress mediators (Shimizu et al, 2010). Consistent with this, pharmacological or genetic disruptions in $\mathrm{CB} 1$ receptor signaling increase splenic NE levels (Simkins et al, 2014), facilitate the release of catecholamines by the SNS induced by CRH (Shimizu et al, 2010), and induce changes in gastrointestinal function and anxiety mediated by an increase in SNS activity (Bellocchio et al, 2013). These data indicate that $\mathrm{CB} 1$ receptors are widely expressed on sympathetic nerve terminals and act to suppress the release of catecholamines. Consistent with this, repeated administration of THC to humans has been found to produce a physiological state consistent with a reduced sympathetic drive and an enhanced parasympathetic drive (Benowitz and Jones, 1977).

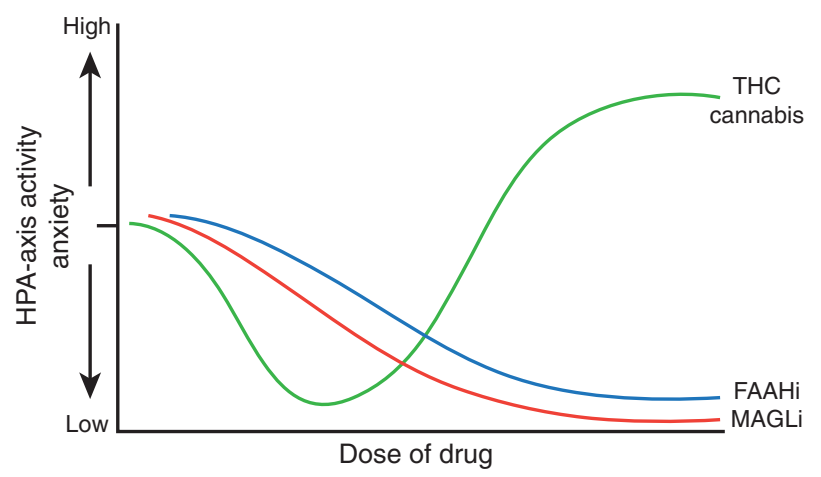

Figure 2. Differential dose-response relationships between cannabis/ THC and eCBs augmentation approaches in the regulation of HPA-axis function and anxiety behaviors. THC and cannabis can reduce HPA-axis function in response to stress and decrease anxiety at low doses, however, at higher doses they can increase HPA-axis function and increase anxiety-like behaviors in animals and precipitate anxiety and panic-like symptoms in humans. In contrast, eCB augmentation via FAAH or MAGL inhibition (FAAHi and MAGLi, respectively) generally exerts mono-phasic dose-dependent reductions in HPA-axis activation and anxiety-like behaviors. 
Collectively, these data present a complex story of how eCB signaling interacts with neuroendocrine systems, and how cannabinoid administration could modulate neuroendocrine function. Specifically, CRH release compromises AEA signaling, while glucocorticoid hormones seem to promote the release of both AEA and 2-AG. eCB signaling at $\mathrm{CB} 1$ receptors, in turn, seems important to constrain many aspects of the stress response and help promote adaptation to repeated stress exposure. In contrast, exogenous cannabinoids including THC exert opposing dosedependent effects on neuroendocrine activation (Figure 2). eCB signaling at CB1 receptors on sympathetic terminals is also capable of dampening the release of catecholamines from sympathetic terminals and thus reduce adrenergic signaling in the periphery.

\section{CANNABINOID ACTIONS WITHIN CORTICO-AMYGDALA CIRCUITS}

Given the consistent recognition of the alterations in prefrontal and amygdalar activity and coupling in PTSD, it is important to examine the impact eCB signaling, as well as cannabinoids themselves, have on neural activity in these circuits (see Gunduz-Cinar et al, 2013a; McLaughlin et al, 2014 for further discussion on how eCB signaling modulates excitability in these structures under conditions of stress). With respect to the amygdala, CB1 receptors are found on both glutamatergic and GABAergic axon terminals (Katona et al, 2001; Ramikie and Patel, 2012). Examining rapid forms of eCB signaling within the amygdala, such as depolarization-induced suppression of inhibition (DSI) or depolarization-induced suppression of excitation (DSE), has demonstrated that both DSI and DSE are found across several sub-nuclei of the amygdala indicating that eCB signaling can regulate both excitatory and inhibitory synaptic transmission in this area (Katona et al, 2001; Kodirov et al, 2010; Ramikie et al, 2014; Zhu and Lovinger, 2005). Similarly, studies employing exogenous CB1 receptor agonists have also found that activation of CB1 receptors can suppress both glutamatergic and GABAergic synaptic transmission (Azad et al, 2003; Domenici et al, 2006; Katona et al, 2001). However, when looking at actual firing rates of neurons, cannabinoids cause a reduction in neural activity within the amygdala (Perra et al, 2008; Pistis et al, 2004), which has led to the suggestion that activation of CB1 receptors on glutamatergic terminals in the amygdala can override the suppression of GABA release, and thus the net effect of $\mathrm{CB} 1$ receptor activation in the amygdala may be to reduce neuronal activity (Azad et al, 2003). Neuroimaging studies in humans have generally supported the hypothesis that cannabinoids act to reduce neuronal activity in the amygdala, and daily cannabis use or acute administration of a low dose of THC to humans have both been found to reduce amygdala reactivity in response to aversive emotional stimuli (Cornelius et al, 2010; Gruber et al, 2009; Phan et al, 2008; Rabinak et al, 2014). Genetic variance in the eCB system also provides corollary evidence of how eCB signaling can reduce amygdala neuronal activity. Specifically, a functional polymorphism in the FAAH gene (C385A) results in a destabilization of the FAAH protein and a subsequent reduction in AEA hydrolysis and elevation in constitutive AEA signaling (Chiang et al, 2004; Dincheva et al, 2015; Sipe et al, 2002; Spagnolo et al, 2016). Humans bearing the A allele of this polymorphism exhibit increased AEA levels and a blunting of threat-cue-induced amygdala reactivity similar to THC or chronic cannabis users (Demers et al, 2016; Gunduz-Cinar et al, 2013a; Hariri et al, 2009). Consistent with this, a mouse line bearing the C385A FAAH polymorphism exhibits reduced neuronal activity, as determined by c-fos induction, within the amygdala following exposure to novel environment (Dincheva et al, 2015). Taken together, these data support the argument that both eCB signaling and exogenous cannabinoids can reduce neuronal activity within the amygdala under some conditions.

While the PFC has many subdivisions, particularly within the human brain relative to the rodent brain, we will focus our discussion on the vmPFC in humans and its putative orthologue, the medial PFC, in the rodent brain, given their overlap in connectivity and importance in the regulation of stress, fear, and anxiety. With respect to eCB signaling in this structure, there does appear to be cortical layer-dependent differences, as well as age-dependent effects, on the ability of eCB signaling to regulate GABAergic and glutamatergic transmission. Specifically, in pre-pubertal animals, eCB signaling predominately suppresses glutamatergic transmission and reduces neuronal excitability within the mPFC (Auclair et al, 2000; Fortin and Levine, 2007; Heng et al, 2011). However, in adolescent and adult rodents, CB1 receptor expression and function decrease on excitatory terminals in the mPFC and have a much less significant impact on glutamate release in the adult $\mathrm{MPFC}$, relative to the pre-pubertal mPFC (Heng et al, 2011). In the adult mPFC, $\sim 98 \%$ of CB1 receptors are localized to GABAergic terminals in layer $\mathrm{V}$ of the mPFC (Hill et al, 2011b), and activation of $\mathrm{CB} 1$ receptors primarily acts to reduce GABA release, dampen inhibition on principal neurons in the mPFC, and increase the activation of these neurons (Chiu et al, 2010; Hill et al, 2011b; Ji and Neugebauer, 2014; Kiritoshi et al, 2016; Pistis et al, 2002; Wedzony and Chocyk, 2009). Consistent with this, THC administration increases neural activity in the vmPFC in humans during emotionally relevant tasks (Rabinak et al, 2014).

In addition to patterns of reactivity within the vmPFC and amygdala, coupling between these structures also seems to be modulated by eCB signaling and cannabinoids. For example, both rodents and humans bearing the A allele of the C385A FAAH polymorphism have enhanced structural and functional connectivity between the vmPFC and the amygdala (Dincheva et al, 2015; Gee et al, 2016). Similarly, acute administration of low-dose THC increases the functional coupling of the amygdala and the vmPFC during emotionally salient tasks (Gorka et al, 2014). 
Taken together, these data indicate that in the adult brain, cannabinoids have the ability to reduce neuronal activity within the amygdala, increase neuronal activity within the vmPFC, and increase the functional coupling of these structures. This constellation of effects is the opposite of the aberrant patterns of activity and coupling that have been found in PTSD populations, supporting the hypothesis that cannabinoids could influence PTSD symptomatology by reducing hyperactivity of the amygdala, reversing hypoactivity of the vmPFC, and increasing the top down control of the amygdala. Although further studies are clearly required to confirm this hypothesis, it provides a compelling heuristic framework to guide subsequent preclinical and clinical studies into the role of cannabinoids in the regulation of PTSD symptomology and related underlying biological substrates.

\section{ENDOCANNABINOIDS, CANNABINOIDS, AND ANXIETY}

Anxiety symptoms are highly prevalent in PTSD, and up until the latest version of the DSM, when it was moved to its own category of trauma- and stress-related disorder, PTSD was categorized as an anxiety disorder. As such, understanding the role $\mathrm{eCB}$ signaling plays in, and the impact of cannabinoids have on, anxiety is germane to establishing the effect they could have on PTSD symptoms. eCB signaling is known to be an important regulator of anxiety, and exogenous cannabinoids are widely accepted to have profound effects on anxiety in both humans and rodents. This section will summarize the current state of knowledge regarding the role of $\mathrm{eCB}$ signaling, and the impact of cannabinoids, on anxiety-related behavior (Lutz et al, 2015; Moreira and Wotjak, 2010; Patel et al, 2017).

Initial insight into the role of $\mathrm{eCB}$ signaling in anxiety-like behavioral responses was obtained through the development of selective $\mathrm{CB} 1$ receptor antagonists and extensive analysis of CB1 KO mice. Blockade of CB1 receptors increases anxiety in several measures of unconditioned or innate anxiety (Bellocchio et al, 2013; Blasio et al, 2014; GambleGeorge et al, 2013; Haller et al, 2004; Komaki et al, 2014; Litvin et al, 2013; Navarro et al, 1997; O'Brien et al, 2013; Patel and Hillard, 2006; Rodgers et al, 2005; Simone et al, 2015; Sink et al, 2010; Thiemann et al, 2009), but some studies have also found opposing results (Degroot and Nomikos, 2004; Griebel et al, 2005; Rodgers et al, 2003). Generally paralleling pharmacological studies, vast majority of studies examining CB1 KO mice demonstrate increased innate anxiety-like behaviors, especially under highly aversive experimental conditions (Bowers and Ressler, 2016; Fride et al, 2005; Hill et al, 2011a; Maccarrone et al, 2002; Martin et al, 2002; Sanchis-Segura et al, 2004). More recently, the development of DAGL inhibitors and DAGL $\alpha$ KO mice has demonstrated increases in anxiety and depressive-like behaviors after pharmacological and genetic depletion of 2AG (Bedse et al, 2017; Jenniches et al, 2016; Shonesy et al,
2014); however these effects are not universally observed (Powell et al, 2015). Consistent with this, local, viralmediated knockdown of DAGL $\alpha$ in the amygdala also produces a mild anxiety-like state in mice (Bluett et al, 2017). Similarly, hippocampal overexpression of MAGL, which decreases 2-AG levels, increases anxiety-related behaviors (Guggenhuber et al, 2015). Importantly, recent studies using acute pharmacological DAGL inhibition indicate that 2-AG depletion causes anxiety-like behaviors that can be reversed by a CB1 agonist, such as THC (Bedse et al, 2017; Bluett et al, 2017). Similar to the 2-AG depletion studies, PFC-specific reductions in AEA levels following viral-mediated overexpression of FAAH also increases anxiety-like behaviors in rats (Rubino et al, 2008). More so, stress-induced reductions in AEA signaling, as discussed above, are known to produce an anxiety-like state (Gray et al, 2015; Hill et al, 2013b; Lomazzo et al, 2015; Rossi et al, 2010). Taken together, these data indicate that $\mathrm{eCB}$ signaling by 2-AG and AEA serve anxiolytic functions, and that depletion of on-demand or tonic eCB signaling results in an anxiogenic-like behavioral phenotype.

Consistent with the loss-of-function studies described above, pharmacological and genetic augmentation of $\mathrm{eCB}$ signaling via inhibition or deletion of $2-A G$ and AEA degradation decreases anxiety-like behaviors in a variety of preclinical models. For example, pharmacological inhibition of FAAH decreases unconditioned anxiety-like behaviors behavior in rats and mice in an array of behavioral tests including the light-dark box, the elevated-plus maze, the open-field test, and the novelty-induced suppression of feeding task (Duan et al, 2016; Hill et al, 2007; Kathuria et al, 2003; Kinsey et al, 2011; Moise et al, 2008; Morena et al, 2016a; Naidu et al, 2007; Patel and Hillard, 2006; Scherma et al, 2008). Moreover, genetic deletion of FAAH decreases anxiety-like behaviors via a CB1-dependent mechanism (Kathuria et al, 2003; Moreira et al, 2008). Interestingly, these effects seem to be amplified under conditions of high environmental averseness or after stress exposure (Haller et al, 2009; Haller et al, 2013; Hill et al, 2013b; Naidu et al, 2007; Patel and Hillard, 2006). Furthermore, mice bearing the C385A FAAH polymorphism exhibit reduced anxiety (Dincheva et al, 2015; Gee et al, 2016). Similar to the effects of AEA signaling, pharmacological augmentation of 2-AG via MAGL inhibition produces modest reductions in unconditioned anxiety-like behaviors under basal, nonstressed conditions (Almeida-Santos et al, 2013; Bluett et al, 2017; Busquets-Garcia et al, 2011; Kinsey et al, 2011; Morena et al, 2016a; Sciolino et al, 2011), while effects under environmentally aversive conditions appear more consistent (Bedse et al, 2017; Sciolino et al, 2011). The anxiolytic effects of MAGL inhibition in most cases is mediated via activation of CB1 receptors ((Bluett et al, 2017; Morena et al, 2016a; Sciolino et al, 2011), but see (Busquets-Garcia et al (2011)) for a potential role of $\mathrm{CB} 2$ receptors). While MAGL KO mice could represent an alternative mechanism to examine the effects of 2-AG augmentation on anxiety-like behaviors, prolonged maximal MAGL inhibition, and sustained 2-AG 
signaling, results in compensatory $\mathrm{CB} 1$ downregulation (Schlosburg et al, 2010), somewhat limiting the utility of this model. Additional approaches to augment eCB signaling including putative transport inhibition and COX-2 inhibition also produce anxiolytic effects via eCB augmentation (Bortolato et al, 2006; Campos et al, 2010; Gamble-George et al, 2016; Hermanson et al, 2013; Naderi et al, 2008; Patel and Hillard, 2006). Together these data strongly indicate that eCB signaling reduces innate, unconditioned anxiety.

Exogenous cannabinoids exert a relatively similar effect to that seen after facilitation of eCB signaling, although there appears to be a much more sensitive dose dependency of these effects. Low doses of CB1 receptor agonists consistently results in a reduction of anxiety-like behavior (Haller et al, 2004; Hill and Gorzalka, 2004; Rey et al, 2012; Rubino et al, 2007), while higher doses of agonists produce an increase in anxiety (Hill and Gorzalka, 2004; Rey et al, 2012). This biphasic dose-dependent difference is consistent with the impact of cannabis and THC exposure in humans, where increasing doses of THC are associated with a greater likelihood of developing adverse, anxiogenic response (Figure 2)(Moreira and Wotjak, 2010).

From a cellular perspective, genetic studies have revealed that, while global deletion of $\mathrm{CB} 1$ receptors increases unconditioned anxiety, genetic reconstitution of $\mathrm{CB} 1$ receptors within forebrain glutamatergic neurons substantially mitigates this phenotype (Ruehle et al, 2013). Although deletion of CB1 receptors from only forebrain glutamatergic neurons is insufficient to increase unconditioned anxiety, the fact that $\mathrm{CB} 1$ receptors on glutamatergic terminals is required for the anxiolytic effects of direct $\mathrm{CB} 1$ receptor agonists (Rey et al, 2012), strongly suggests CB1 receptor signaling within cortical glutamatergic circuits is important for the anxiolytic effects of eCB signaling and exogenous cannabinoids. The adverse, anxiogenic effects of higher doses of cannabinoids appear to be mediated by CB1 receptors on GABAergic terminals (Rey et al, 2012). Interestingly, mice lacking CB1 expression within serotonergic neurons also display increased anxiety and reduced sociability (Dubreucq et al, 2012; Haring et al, 2015), suggesting a role for eCBmediated modulation of monoaminergic circuits could also play a role. Studies performing site-specific manipulations of eCB signaling highlight the importance of $\mathrm{eCB}$ signaling in the mPFC and amygdala as important sites of action mediating these effects (Bluett et al, 2017; Duan et al, 2016; Gray et al, 2015; Morena et al, 2016a), which likely relates to the ability of $\mathrm{eCB}$ signaling in these structures to regulate excitatory and inhibitory neurotransmission (as discussed above). Defining the precise circuit mechanisms by eCB signaling and exogenous cannabinoids modulate anxietyrelated behaviors represents a critical area of further investigation.

With respect to humans, it appears that $\mathrm{eCB}$ signaling similarly acts to reduce anxiety. Humans bearing the C385A FAAH polymorphism have been repeatedly found to exhibit lower rates of anxiety (Dincheva et al, 2015; Gee et al, 2016; Gunduz-Cinar et al, 2013b; Spagnolo et al, 2016). Similarly, circulating levels of AEA are negatively correlated to increasing levels of anxiety, both at rest and in response to stress exposure (Dlugos et al, 2012; Hill et al, 2008b). Importantly, however, was the finding that administration of CB1 receptor antagonists to humans resulted in a significant increase in indices of anxiety, a reported side effect in clinical trials that contributed to the removal of $\mathrm{CB} 1$ receptor antagonists as a pharmacological tool to treat obesity (Christensen et al, 2007; Moreira et al, 2009). Consistent with this, recreational use of cannabis is often associated with reductions in anxiety (Halikas et al, 1971). Large-scale surveys have identified that the majority of chronic cannabis users do so because of its stress-reducing and anxiolytic properties (Bonn-Miller et al, 2007b; Reilly et al, 1998; Temple et al, 2014). More so, many studies have identified that individuals with anxiety disorders, particularly social anxiety disorder and PTSD, use cannabis in an attempt to regulate their anxiety symptoms (Boden et al, 2013; Buckner et al, 2006; Buckner and Zvolensky, 2014; Buckner et al, 2012; Cougle et al, 2011; Van Dam et al, 2012). In line with these findings, several clinical studies have found that similar to its efficacy in PTSD, Nabilone treatment can effectively reduce clinically relevant anxiety disorders, or suppress experimentally induced anxiety, often to the same degree seen with conventional anxiolytics such as benzodiazepines (Fabre and McLendon, 1981; Nakano et al, 1978). Together, these findings clearly demonstrate the importance of eCB signaling in the regulation of anxiety, and highlight that low doses of exogenous cannabinoids typically reduce anxiety in both humans and rodents.

\section{ENDOCANNABINOIDS, CANNABINOIDS, AND EMOTIONAL MEMORY}

Any discussion of therapeutics for PTSD has to consider the impact the drugs have on emotional memory. As discussed earlier in this review, the development of PTSD is believed to be related to fundamental dysregulation in learning and memory processes. As such, understanding the role of eCB signaling, and the impact of exogenous cannabinoids, on these processes is necessary in determining the role this system may play in PTSD. In this section, we examine eCB effects on memory consolidation, retrieval, and extinction of emotional experiences in animal models of conditioned learning and we make parallelism with the effects induced by the direct agonists. For a more detailed discussion of the impact of eCB signaling and cannabinoids on emotional memory please refer to the recent reviews (de Bitencourt et al, 2013; Morena and Campolongo, 2014a).

\section{Memory Consolidation}

With respect to the initial consolidation of emotionally salient memories, although there is one report showing that systemic administration of the FAAH inhibitor URB597 impairs the acquisition and early consolidation of contextual fear conditioning (Burman et al, 2016), studies examining 
local manipulation of eCB signaling in the $\mathrm{mPFC}$ and amygdala, as well as the hippocampus, have generally found that $\mathrm{eCB}$ signaling is requisite for the consolidation of emotionally salient memories. In this regard, de Oliveira Alvares et al (2008) reported enhancing effects of endogenous hippocampal administration of AEA after inhibitory avoidance training. Accordingly, exogenous potentiation of the hippocampal eCB tone by local infusion of a FAAH inhibitor enhances memory for inhibitory avoidance training (Morena et al, 2014b). The above described findings, together with the observation that a CB1 receptor antagonist impairs hippocampal memory consolidation for high intensity contextual fear condition training (de Oliveira Alvares et al, 2010), demonstrate that, in opportune conditions, the eCB system in the dorsal hippocampus is activated on demand to facilitate the consolidation of an aversive memory. Fear memory is also impaired by blockade of $\mathrm{eCB}$ transmission in another crucial brain area for memory consolidation, the basolateral nucleus of the amygdala (Bucherelli et al, 2006). Accordingly, potentiation of the AEA signaling in the BLA, induced with local administration of a FAAH inhibitor, enhanced memory for inhibitory avoidance training (Morena and Campolongo, 2014a). Intriguingly, similar effects were seen with FAAH inhibition inducing enhancing effects on memory for emotional experiences (Morena and Campolongo, 2014a) and with $\mathrm{CB} 1$ receptor antagonism inducing impairing effects on fear memory formation (Tan et al, 2010) when infused in the mPFC. On the basis of the observation that CB1 receptor activation in the BLA and PFC produces effects going in the same enhancing direction, Draycott et al (2014) demonstrated that CB1 receptor antagonism completely blocks the induction of LTP within the BLA-PFC circuit at the same dose that can block the formation of associative fear memories. Furthermore, functional disconnection experiments performed by contralateral blockade of $\mathrm{CB} 1$ receptor signaling in the BLA or PFC revealed that the acquisition of fear memory within this pathway requires simultaneous CB1 receptor activation in both regions (Draycott et al, 2014).

Interestingly, the impact of exogenous cannabinoids on consolidation of emotionally salient memories appears to be somewhat inconsistent with what was seen with modulation of eCB signaling. For example, it appears that systemic administration of CB1 receptor agonists impairs consolidation for emotionally salient memories (for a review see Morena and Campolongo (2014a); Morena et al (2014b)). Similar effects are seen if $\mathrm{CB} 1$ receptor agonists are administered directly into the hippocampus, with posttraining infusion of a $\mathrm{CB} 1$ receptor agonist producing an impairment in memory consolidation for aversive training (Jamali-Raeufy et al, 2011; Moshfegh et al, 2011; Zarrindast et al, 2011). With respect to the BLA, while one report has found that administration of a $\mathrm{CB} 1$ receptor agonist into the BLA impairs consolidation of emotional memories (Kuhnert et al, 2013), most other studies report findings more consistent with what has been seen following facilitation of
eCB signaling. Specifically, local infusion of a CB1 receptor agonist directly into the BLA enhances memory for emotional arousing inhibitory avoidance training through activation of CB1 receptors, while intra-BLA disruption of CB1 receptor transmission impairs it (Campolongo et al, 2009). Interestingly, activation of CB1 receptors into the PFC strongly potentiates fear memory formation in an olfactory fear conditioning paradigm and blockade of intra-PFC CB1transmission blocked the formation of fear memory (Tan et al, 2010).

These findings demonstrate that appropriate emotional processing and memory formation require integrative $\mathrm{CB} 1$ receptor signaling across this cortico-limbic circuit. Hyperor hypo-activation of the cannabinoid system within the hippocampus, the BLA, or the PFC is sufficient to cause pathological amplification of normally neutral stimuli, or, alteration of emotional salience toward environmental stimuli that would normally produce adaptive associative memories (Morena and Campolongo, 2014a; Morena et al, 2014b; Tan et al, 2014). Global activation of CB1 receptors through systemic administration of exogenous cannabinoids appears to impair consolidation, a finding which is generally consistent with studies examining non-emotional memory consolidation, but site-specific activation of CB1 receptors in the amygdala and mPFC still reinforce the hypothesis that CB1 receptor activation in these sites is important for emotional memory consolidation.

\section{Memory Retrieval}

Memory retrieval is another relevant process by which eCB signaling or cannabinoids could influence emotional memory stability and expression. Reports on eCB effects on the retrieval of memory for emotional learning are scarce. Interestingly, the relationship between $\mathrm{eCB}$ signaling and glucocorticoids becomes highly relevant in this context, as the ability of glucocorticoids to impair memory retrieval of a context-dependent emotional memory is mediated by a recruitment of 2-AG signaling in the dorsal hippocampus (Atsak et al, 2012). A similar effect has been found in the Morris water maze task, where the potentiation of 2-AG signaling within the hippocampus induces an impairment of spatial memory retrieval, but only under conditions of elevated stress (Morena et al, 2015). As both of these experiments demonstrated selective elevations in 2-AG associated with the impairing effect of stress or glucocorticoids, and inhibition of FAAH did not influence memory retrieval, this suggests that it is specifically an association between glucocorticoids and 2-AG signaling that is important for the suppression of emotionally aversive memory retrieval. Similar effects are seen with the administration of exogenous cannabinoids. Systemic administration of THC or other CB1 receptor agonists impairs memory retrieval in a step-through inhibitory avoidance task (Mishima et al, 2001), while local administration of a CB1 receptor agonist into the BLA or the PFC (Kuhnert et al, 2013) or the CA1 region of the hippocampus (Atsak et al, 2012; Piri and 
Zarrindast, 2011; Segev and Akirav, 2011) impairs the retrieval of emotionally aversive memories. The consistency and reproducibility of these limited findings suggest that $\mathrm{eCB}$ signaling and $\mathrm{CB} 1$ receptor activation impairs the retrieval of memory for emotional experiences.

\section{Memory Extinction}

Finally, and potentially most importantly, is the role of eCB signaling on the extinction of emotionally aversive memories, a process known to be impaired in individuals with PTSD and that may contribute to the indelible nature of traumatic memories in this disease. To date, overwhelming evidence from animal models suggest that $\mathrm{eCB}$ signaling is critically involved in the extinction of emotionally aversive memories. Both genetic and pharmacological experiments demonstrate that potentiation of the $\mathrm{eCB}$ signaling and subsequent activation of cannabinoid receptors in the amygdala facilitate fear extinction in rodents (Chhatwal et al, 2009; Marsicano et al, 2002). Following extinction training, eCB levels in the amygdala, but not in the PFC, are elevated (Marsicano et al, 2002; Gunduz-Cinar et al, 2013a, b). In accordance with this, deletion of CB1 receptor in mice impairs extinction of aversive memory, indicating that $\mathrm{eCB}$ signaling is recruited during extinction of emotional memories and, in turn, is essential for the appropriate quenching of fear behaviors (Marsicano et al, 2002). This process may relate specifically to the ability of eCB signaling to promote habituation to fearful stimuli and thus reduce fear expression over time (Kamprath et al, 2006) and seems to involve CB1 receptors on glutamatergic terminals (Kamprath et al, 2009), as well as, possibly, the release of cholecystokinin from a discrete population of interneurons within the amygdala (Chhatwal et al, 2009). Further support for the importance of amygdalar eCB signaling being particularly relevant for fear extinction is that fact that local manipulation of eCB signaling directly within the BLA modulates fear extinction (Gunduz-Cinar et al, 2013b), as well as the fact that alternate treatments which have been found to enhance fear extinction, such as treatment with the SSRI fluoxetine (Gunduz-Cinar et al, 2016) or modulation of dietary polyunsaturated fatty acids (Yamada et al, 2014), recruit eCB signaling within the amygdala to promote extinction.

With regard to pharmacological studies, several reports demonstrate that potentiation of AEA signaling, through inhibition of FAAH or eCB uptake, enhance extinction of contextual fear conditioning for both recent and remote memory (Bowers and Ressler, 2015a; Gunduz-Cinar et al, 2013b; Laricchiuta et al, 2013; Pamplona et al, 2008; Pamplona and Takahashi, 2006). Consistently, mice bearing the FAAH C385A polymorphism exhibit accelerated fear extinction relative to wild-type counterparts, again supporting the hypothesis that elevated AEA signaling enhances fear extinction (Dincheva et al, 2015). In accordance to the importance of eCB signaling for fear extinction demonstrated through the impairment in this process seen in CB1
$\mathrm{KO}$ mice, CB1 receptor antagonists impair extinction of auditory (Bowers and Ressler, 2015a; Gunduz-Cinar et al, 2013b; Marsicano et al, 2002; Pickens and Theberge, 2014) as well as contextual fear conditioning (Pamplona et al, 2008; Pamplona and Takahashi, 2006; Reich et al, 2008; Suzuki et al, 2004). The ability of glucocorticoids to promote fear extinction involves a recruitment of eCB signaling, similar to memory retrieval, as the extinction-promoting effects of glucocorticoids are sensitive to CB1 receptor antagonism (Bitencourt et al, 2014). These extinction-promoting effects of eCB signaling, however, appear to be primarily mediated by AEA and not 2-AG. Two recent reports have demonstrated that inhibition of MAGL to enhance 2-AG signaling impairs fear extinction and promotes fear memory expression, an effect which is believed to be mediated by CB1 receptors on GABAergic neurons (Hartley et al, 2016; Llorente-Berzal et al, 2015). This parallels the findings with anxiety whereby biphasic effects of cannabinoids are differentially mediated by $\mathrm{CB} 1$ on glutamatergic vs GABAergic terminals.

Interestingly, administration of the CB1 receptor antagonist Rimonabant attenuates memory extinction in other aversively motivated behavioral tasks as well (eg, inhibitory avoidance and Morris water maze) but failed to affect extinction in an appetitive-motivated operant conditioning task (Niyuhire et al, 2007; Varvel et al, 2005, 2007). This suggests there is specificity to eCB signaling in the extinction of memories, which have a high emotional load associated with them. Similar extinction-facilitating effects have also been found following systemic or intracerebroventricular administration of a $\mathrm{CB} 1$ receptor agonist (Pamplona et al, 2008; Pamplona and Takahashi, 2006). Consistent with these global effects of CB1 receptor activation, intra-hippocampal administration of a $\mathrm{CB} 1$ receptor agonist facilitates extinction of inhibitory avoidance training (Abush and Akirav, 2010; de Oliveira Alvares et al, 2008), while CB1 receptor antagonism impairs extinction learning when given either in the dorsal hippocampus (Abush and Akirav, 2010) or in the BLA (Ganon-Elazar and Akirav, 2009). Intra-CA1 infusion of a CB1 receptor antagonist also impaired fear extinction in the contextual fear conditioning paradigm (de Oliveira Alvares et al, 2008).

The effects of eCB signaling and cannabinoids on extinction in humans nicely parallels the preclinical data from fear conditioning and inhibitory avoidance paradigms. Elevations in AEA signaling in humans, associated with the FAAH C385A polymorphism, are related to more rapid fear extinction learning curves, with no differences in initial fear learning, relative to those possessing the prototypical ancestral FAAH gene (Dincheva et al, 2015). Pharmacological approaches have yielded similar findings, as studies administrating THC to humans prior to extinction training have found increased retention of extinction memory in those receiving $\mathrm{THC}$ relative to those receiving placebo (Rabinak et al, 2013, 2014). Similarly, the non-psychoactive cannabinoid CBD has also been found to enhance the consolidation of extinction memory (Das et al, 2013), 
suggesting that additional constituents of cannabis could also promote fear extinction. Collectively, these data create a compelling argument that cannabinoids could modulate multiple aspects of emotional memory processes. While the impact on initial consolidation would actually suggest eCB signaling may promote memory consolidation, the fact that eCB signaling can both impair retrieval and promote extinction of emotionally aversive memories suggests that from a therapeutic standpoint, that is once PTSD has been established, the ability of cannabinoids to quench emotionally aversive memories could be of benefit to individuals suffering from PTSD.

\section{ENDOCANNABINOIDS, CANNABINOIDS, AND INFLAMMATORY PROCESSES}

Given the recent findings of the relationship between inflammatory systems and PTSD, the impact of eCB signaling and cannabinoids on inflammatory processes is of increasing interest. Within the context of the immune system, the role of the CB2 receptor, as opposed to the CB1 receptor, has been the focus of the majority of research and, as such, will be the focus of the following discussion (see (Turcotte et al (2016)) for a more in-depth review of CB2 and inflammatory processes).

CB2 receptors are primarily expressed on macrophage/ monocyte cells, including resident microglia in the brain, and to a lower degree on $\mathrm{T}$ cells (Maresz et al, 2007; Turcotte et al, 2016). CB2 receptor activation on immune cells generally acts to reduce inflammatory processes, including suppressing the release of pro-inflammatory cytokines (such as TNF-a, IL-1b, and IL-6), inhibiting the expression of adhesion molecules that initiate the process of leukocyte migration, suppressing the release of chemoattractant molecules from dendritic cells, countering NF $k$ B-mediated gene transcription and dampening cellular oxidative stress (Boorman et al, 2016; Chiurchiu et al, 2015; McCoy, 2016; Rom and Persidsky, 2013; Turcotte et al, 2016). Moreover, in microglia, CB2 receptor activation promotes an M2 phenotype, which is characterized by the release of antiinflammatory cytokines and the engagement in reparative functions (Lin et al, 2017; Mecha et al, 2015). As such, the CB2 receptor exerts a multitude of anti-inflammatory effects on immune cells.

Interestingly, $\mathrm{CB} 2$ receptor expression is inducible and dynamic, such that expression levels of CB2 at rest, especially on microglia, are quite low, and are rapidly induced in response to inflammatory stimuli (Maresz et al, 2005). This suggests that CB2 receptor activation acts more as regulatory signal, which prevents hyperactivation of immune cells and acts to buffer the magnitude of inflammatory processes once the pro-inflammatory cascade has been initiated. Importantly, genetic or pharmacological disruption of CB2 receptor signaling increases the magnitude and propensity of a host of inflammatory conditions in animal models, such as colitis, multiple sclerosis, traumatic brain injury, neurodegenerative diseases, and ischemia-reperfusion injuries (Batkai et al, 2007; Maresz et al, 2007; Palazuelos et al, 2008; Storr et al, 2009; Turcotte et al, 2016). Consistent with this, activation of $\mathrm{CB} 2$ receptors provides some degree of protection in limiting the magnitude or reducing the disease expression of nearly every type of inflammatory disease investigated to date, including all of those listed above, which are worsened by CB2 receptor blockade (Batkai et al, 2007; Maresz et al, 2007; Palazuelos et al, 2008; Storr et al, 2009; Turcotte et al, 2016). In line with this, augmentation of either 2-AG or AEA signaling has been found to be protective as well in many inflammatory conditions, such as animal models of multiple sclerosis, colitis, and traumatic brain injury, in a CB2 receptor-dependent manner (Alhouayek et al, 2011; Jiang et al, 2015; Sardinha et al, 2014; Storr et al, 2008; Tchantchou et al, 2014; Wen et al, 2015). Similarly, inhibition of FAAH or MAGL, to elevate AEA or 2-AG signaling, respectively, can reduce the inflammatory response, including microglial activation, after acute inflammation produced by the inflammogen LPS (Grabner et al, 2016; Hernangomez et al, 2012; Kerr et al, 2012, 2013; Malek et al, 2015; Roche et al, 2008; Tham et al, 2007). Importantly, eCB signaling at $\mathrm{CB} 2$ receptors has also been found to limit the neuroinflammatory response produced by repeated stress exposure (Zoppi et al, 2014).

Many studies have been done in human immune cell lines to produce comparable results, suggesting that cannabinoids exhibit the potential to exert anti-inflammatory effects in humans as well. This is consistent with the fact that the most common form of disease for which someone employs cannabis in a medical domain appears to be chronic disease states associated with inflammatory processes, such as multiple sclerosis, colitis, arthritis, or fibromyalgia (Aggarwal et al, 2009; Katz et al, 2017; Weiss and Friedenberg, 2015). More so, one study examined circulating levels of cytokines in cannabis users with or without multiple sclerosis and found that regardless of disease diagnosis, individuals not naive to cannabis use exhibited lower levels of circulating pro-inflammatory cytokines, supporting an anti-inflammatory effect of cannabinoids in humans (Sexton et al, 2014).

Taken together, these data indicate that eCB signaling is an important regulator of inflammatory processes, with deficits in $\mathrm{eCB}$ signaling favoring a state of hyperinflammation, while elevations in eCB signaling confer anti-inflammatory effects. As mentioned above, animal studies have found that $\mathrm{eCB}$ signaling is important in constraining the effects of stress on neuroinflammation, however, to date there is no evidence linking deficient eCB signaling to hyperinflammatory states (as seen in PTSD), or any clinical data indicating that administration of cannabinoids to individuals with PTSD has any impact on inflammatory processes. As such, the relationship between $\mathrm{eCB}$ signaling and inflammation in PTSD remains entirely speculative, but given the association of hyperinflammatory states with PTSD, the ability to cannabinoids to suppress the release of pro-inflammatory cytokines could be an additional mechanism by which 
cannabinoids could be ameliorative in PTSD and should be an area of future research.

\section{ENDOCANNABINOIDS, CANNABINOIDS, AND SLEEP}

Sleep disturbances represent a major domain of PTSD symptomatology, and the frequency of violent traumatic nightmares is a significant contributor to both the progressive sensitizing nature of the disease as well as significant source of disease burden given the impairments poor quality of sleep have on daily functioning (Ross et al, 1989). In this regard it is interesting to note that, as described earlier, much of the anecdotal reports of cannabis use in PTSD are motivated by the somnogenic properties of cannabis. This is consistent with the clinical data indicating that a primary domain by which cannabinoids may improve general wellbeing in PTSD is through a suppression of nightmares, a reduction in arousal and an enhancement of time spent sleeping (Cameron et al, 2014; Fraser, 2009; Jetly et al, 2015). Interestingly, studies of sleep architecture in humans have found that administration of cannabinoids prior to sleep can reduce the amount of time spent in REM sleep (Feinberg et al, 1976; Feinberg et al, 1975). The occurrence of nightmares in PTSD is believed to occur to during REM sleep and REM sleep phases are believed to be dysfunctional in PTSD (Mellman et al, 1995; Ross et al, 1989, 1994; Singareddy and Balon, 2002). This would suggest that the ability of cannabinoids to suppress REM sleep may be the predominant mechanism by which cannabinoids suppress nightmares.

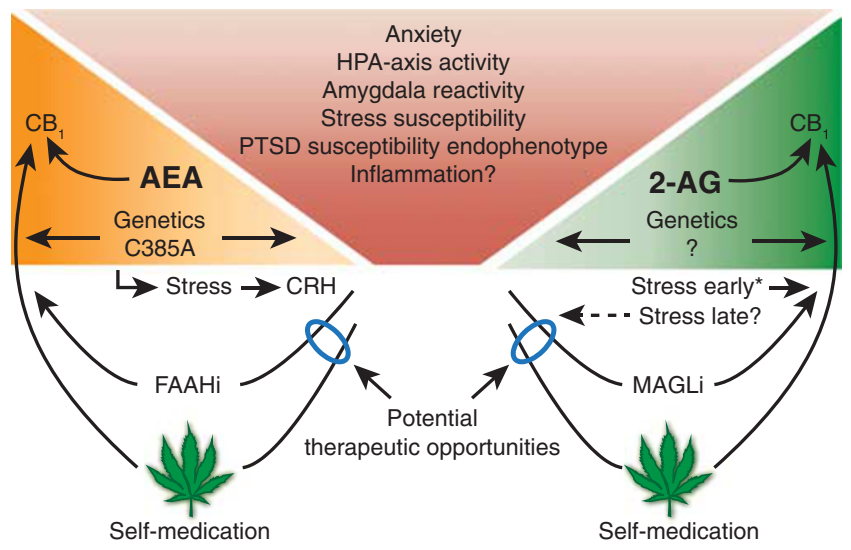

Figure 3. Integrative view of eCBs and exogenous cannabinoids in the pathophysiology and potential treatment of PTSD and related processes. Low levels of AEA and/or 2-AG, triggered by stress or pre-existing due to genetic factors, are associated with a myriad of adverse behavioral and physiological consequences including an increase susceptibility to developing trauma-related psychopathology such as PTSD. Therapeutic eCB augmentation may be able to reverse these pre-existing or stressinduced deficiencies via inhibition of FAAH or MAGL activity (FAAHi and MAGLi, respectively). Similarly, this model predicts some people with eCB deficiencies may use cannabis to self-medicate for anxiety and PTSD symptoms. *'2-AG early’ refers to early relative to stressor onset.
These findings are generally in line with what is known about eCB signaling and sleep (see (Prospero-Garcia et al (2016)) for in depth review on the topic). Several reports have suggested that AEA signaling may be involved in sleep induction (Mechoulam et al, 1997; Murillo-Rodriguez et al, 2003; Murillo-Rodriguez et al, 2001). Similarly, augmentation of eCB signaling alters sleep architecture to promote time spent in NREM sleep and less time in wakefulness (Huitron-Resendiz et al, 2004; Pava et al, 2014, 2016). Consistent with this, disruption of CB1 receptor signaling is known to increase EEG measures of arousal, reduce time spent sleeping, increase wakefulness, and alter sleep architecture, with some evidence suggesting that impairments in CB1 receptor signaling favor an increase in time spent in REM sleep (Pava et al, 2014, 2016; Santucci et al, 1996; Silvani et al, 2014). Studies with exogenous cannabinoids in animals have largely supported the findings that CB1 receptor activation reduces wakefulness and arousal, promotes time spent sleeping, and increases the proportion of sleep time spent in NREM states (Pava et al, 2014, 2016). Importantly, with respect to PTSD, inhibition of FAAH also ameliorates sleep fragmentation and sleep reduction induced by contextual reminders of traumatic stress in mice (Haller et al, 2014). As such, there is clear evidence to support a mechanism by which eCB signaling or cannabinoids could improve sleep quality and reduce nightmares in PTSD through a regulation of sleep states and architecture.

\section{TOWARD AN ENDOCANNABINOID DEFICIENCY HYPOTHESIS OF PTSD AND CANNABINOID-BASED THERAPEUTICS FOR PTSD}

Thus far, a compelling picture emerges from the literature to support the argument that a deficit in eCB signaling could relate to the development of PTSD (Figure 3). First, exposure to stress reduces AEA signaling in cortico-limbic brain regions, and can cause a delayed onset of 2-AG deficiency under some conditions (Hill et al, 2005; Qin et al, 2015; Zhong et al, 2014). As described above, deficiencies in eCB signaling can result in hyperactivity of the amygdala, hypoactivity of the $\mathrm{MPFC}$, impaired regulation of the stress response, including heightened $\mathrm{CRH}$ signaling and SNS activity, elevated levels of basal and stress-induced anxiety, increased retrieval and impaired extinction of emotionally aversive memories, and an increased propensity to develop a state of inflammation. This parallels the aforementioned biological findings derived from PTSD patient populations. From a mechanistic standpoint, this reduction in eCB signaling could be a consequence of reductions in glucocorticoid levels, or a state of glucocorticoid resistance, given the importance of glucocorticoids in modulating eCB release and the relationship that has been found between circulating levels of cortisol and $\mathrm{eCB}$ molecules in humans (Hill et al, 2013a; Hill and McEwen, 2010b; Hill and Tasker, 2012). More so, as the ability of glucocorticoids to exert their effects 
on many processes implicated in PTSD, such as suppression of excitatory transmission in the amygdala (Karst et al, 2010) and inhibitory transmission in the mPFC (Hill et al, 2011b), inhibition of aversive memory retrieval (Atsak et al, 2012) and promotion of fear extinction (Karst et al, 2010), an uncoupling or deficit in the relationship between glucocorticoids and $\mathrm{eCB}$ signaling could significantly contribute to the development of aberrations in cortico-limbic neuronal activation and the regulation of emotional memories as seen in PTSD. Alternately, elevations in $\mathrm{CRH}$ signaling have also been found to compromise AEA signaling (Demers et al, 2016; Gray et al, 2015; Gray et al, 2016; Natividad et al, 2017), representing another mechanism that could potentially contribute to deficient $\mathrm{eCB}$ signaling in PTSD. Alternative non-endocrine mechanisms triggered by stress could also contribute to eCB deficiencies.

In line with this hypothesis, there are also several findings in humans that have implicated a deficit in eCB signaling to PTSD. For example, reductions in the circulating levels of both AEA (Neumeister et al, 2013) and 2-AG (Hill et al, 2013a) are documented in individuals with PTSD, although one group reported elevations in circulating $\mathrm{eCB}$ levels in PTSD (Hauer et al, 2013). Fundamental differences in the nature of PTSD and subject samples across these studies could account for these contradictory findings. Quite interestingly, reductions in circulating levels of AEA in PTSD were associated both with elevated CB1 receptors throughout cortico-limbic structures, presumably as a compensatory response to reduced AEA ligand availability, and were specific to PTSD as none of these changes were seen in trauma-exposed controls (Neumeister et al, 2013). Negative correlations between AEA levels and the degree of intrusive symptoms have also been reported in PTSD patients (Hill et al, 2013a). In line with this, genetic studies in PTSD populations have found that those individuals who possess the FAAH C385A polymorphism exhibit less anxiety and reduced stress reactivity than those with the ancestral wild-type variant of FAAH, along with a specific reduction in the hyperarousal symptoms of PTSD (Spagnolo et al, 2016). As such, it appears that reductions in $\mathrm{eCB}$ signaling may relate to specific symptom clusters within PTSD, which is consistent with the findings of self-report where individuals with PTSD who consume cannabis claim the greatest benefit in the domains of hyperarousal and nightmares.

The findings from preclinical animal studies strongly support the hypothesis that deficits in eCB signaling could contribute to an enhanced vulnerability to the development of pathological changes following exposure to traumatic stress. For example, two recent studies have both demonstrated that following exposure to traumatic stress in rodents, animals which develop pathological changes in emotional behavior similarly exhibit impairments in the ability to recruit eCB signaling within the amygdala (Bluett et al, 2017), as well as the nucleus accumbens (Bosch-Bouju et al, 2016). More so, pharmacological augmentation of eCB signaling in these studies afforded benefit to animals exposed to traumatic stress and favored the development of a resilient phenotype (Bluett et al, 2017; Bosch-Bouju et al, 2016). In agreement with these findings, disruption of eCB signaling directly within the amygdala has explicitly been found to impair normative adaptation to repeated stress exposure (Hill et al, 2010c) and favor the development of a stress vulnerable-like phenotype (Bluett et al, 2017).

An important question that arises from this hypothesis, however, is whether a deficit in eCB signaling would be represented as a stable trait, which renders an individual susceptible to developing psychiatric pathologies, such as PTSD, following exposure to a trauma but has negligible impact on the development of psychiatric illness under benign environmental conditions, or whether a deficit in $\mathrm{eCB}$ signaling in response to a traumatic stressor compromises the initiation of adaptive coping responses that would normally mitigate the development of PTSD. The importance of this distinction relates to the viability of developing a biomarker with the eCB system that would have some degree of predictive value for understanding which individuals would be vulnerable to PTSD prior to exposure to a trauma. If a deficit in eCB signaling is a stable trait that is present before exposure to a trauma, there would be significant value in this for the development of predictive biomarkers; however, if this deficit in $\mathrm{eCB}$ signaling was a latent trait that only emerged after exposure to a trauma, this would suggest that there would not be any predictive value in the eCB system. Human studies, to date, have only examined components of the $\mathrm{eCB}$ system in individuals once they have developed PTSD, preventing any understanding as to whether these changes existed beforehand. Future research with animal studies will likely be the most realistic way to approach this question, and comparisons of circulating levels of eCB can be examined pre- and post-exposure to traumatic stress to determine if there is any predictive value in resting markers of $\mathrm{eCB}$ function to those that go on to develop pathology in response to traumatic stress. These studies would also help to determine if there are any relations between circulating and central eCB levels. While eCBs are lipid molecules and peripheral AEA levels, for example, readily cross the blood-brain barrier and accumulate in the brain (Willoughby et al, 1997), it is not known if changes in circulating $\mathrm{eCB}$ are reflective of changes within the $\mathrm{CNS}$. The fact that circulating AEA levels negatively correlate with CB1 receptor binding densities in the brain (Neumeister et al, 2013) would suggest that there is some relation to central eCB signaling, although this remains speculative. With regard to 2-AG, global deletion of DAGL $\alpha$ reduced brain but not circulating levels of 2-AG, suggesting a degree of uncoupling between central and peripheral pools of this eCB (Shonesy et al, 2014). That being said, given that peripheral $\mathrm{eCB}$ signaling alone is capable of regulating the release of catecholamines from sympathetic terminals and dampening inflammatory processes, deficits in peripheral eCB signaling could still be relevant to some biological changes associated with PTSD even in the absence of alterations in central eCB signaling. 
From a treatment perspective, the body of evidence summarized here in support the hypothesis that augmenting eCB signaling could be a novel therapeutic approach for PTSD. As described in this review, pharmacological elevations in eCB signaling reduce reactivity of the amygdala, enhance activation of the $\mathrm{MPFC}$ and increase its coupling to the amygdala, reduce anxiety, suppress the recall and enhance the extinction of emotionally aversive memories, counter the effects of CRH signaling and produce sympathoinhibition, dampen inflammatory processes, reduce the occurrence of REM sleep and arousal to increase time spent sleeping. These biological changes, many of which are also produced by exogenous cannabinoid receptor agonists but in a more dose-sensitive manner (with higher doses producing opposing effects), are consistent with the profile one would hope to achieve in a medication approach directed at PTSD given that many of these effects are the opposite of the biological abnormalities associated with the disorder.

Moving forward, how can these data and this hypothetical model inform treatment options? Clinical trials investigating these questions have been under development for some time, and it is likely that data from such studies will emerge in the near future. The development of potent and specific FAAH inhibitors, for example, represents a class of drugs which could potentially act as a novel therapeutic option for PTSD. Similarly, MAGL inhibitors are currently being developed and undergoing Phase I trials; however, no public reports have been made as to their safety or efficacy as of yet. MAGL as a target has some limitations, given that prolonged MAGL inhibition, at high doses, can result in desensitization of the eCB system (Schlosburg et al, 2010), which could limit the utility of these drugs. Also, unlike FAAH inhibitors which generally exhibit anxiolytic and anti-fear-like effects in rodents, there is evidence that elevations in 2-AG signaling could enhance fear expression (Llorente-Berzal et al, 2015) and impair short-term fear extinction (Hartley et al, 2016), although other studies have indicated that MAGL inhibitors do possess anxiolytic (Busquets-Garcia et al, 2011; Morena et al, 2016a; Sciolino et al, 2011; Sumislawski et al, 2011; Zhong et al, 2014) and stress-resilient like properties (Bluett et al, 2017; Bosch-Bouju et al, 2016). As such, more research in this area is required to fully understand the potential differential values of these two approaches for therapeutic eCB augmentation.

An important question that would go along with this is the nature of drug administration. For example, as preclinical studies have highlighted the importance of $\mathrm{eCB}$ signaling during fear extinction (Gunduz-Cinar et al, 2013b; Marsicano et al, 2002), one consideration would be to specifically examine the impact of FAAH inhibitor administration prior to cognitive therapies, such as exposure therapy (which models the same principles as extinction training in animals) to determine if facilitation of $\mathrm{eCB}$ signaling can enhance the efficacy of cognitive interventions having longer lasting impact and reducing the occurrence of spontaneous relapse of disease symptomatology. As such, clinical studies in humans at this time are absolutely essential in determining the therapeutic potential of $\mathrm{eCB}$ modulation for the treatment of PTSD.

A final comment should also be made regarding the influence of cannabis use on PTSD. Recent preclinical studies have indicated that THC can reduce anxiety associated with 2-AG deficiency and can reduce stress-induced anxiety in susceptible animals (Bedse et al, 2017; Bluett et al, 2017), which provides some biological plausibility to the selfmedication hypothesis used to explain high rates of cannabis use in patients with PTSD (Cougle et al, 2011) and high degree of symptom-coping motives cited by these patients (Bonn-Miller et al, 2007b)(Figure 3). Consistent with this hypothesis are the anecdotal reports of cannabis use improving quality of life and reducing symptoms in individuals with PTSD (see above). While anecdotes do not represent sound scientific evidence, the consistency of these reports suggests larger-scale rigorous studies are warranted in this area. In this regard, clinical studies into the impact of cannabis use on PTSD symptomatology should be directly addressed to determine if there is a significant benefit of cannabis use in PTSD, and if so, do they outweigh the potential adverse effects of cannabis use including dependence liability. Furthermore, given the potential impact of CBD (Blessing et al, 2015; Jurkus et al, 2016; Rossignoli et al, 2017; Stern et al, 2015), as well as THC, in PTSD, research into the effects of cannabis with different THC: $\mathrm{CBD}$ ratios would be of particular interest. However, an important consideration, in this regard, is that the recognition of the potential negative effects that excess, chronic cannabis use could have on the trajectory of PTSD symptoms. For example, excess, chronic cannabis use has been associated with a reversible downregulation of $\mathrm{CB} 1$ receptors in the brain (Ceccarini et al, 2015; Hirvonen et al, 2012), and both animal and human studies have found that excess cannabis use has been associated with impairments in fear extinction (Lin et al, 2008; Papini et al, 2017), possibly related to an impairment in the native functions of the eCB system. This is consistent with some clinical reports that excess cannabis use may be related to more negative, long-term outcomes in PTSD (Boden et al, 2013; Steenkamp et al, 2017; Wilkinson et al, 2016). As such, while cannabis use may provide benefit for some individuals with PTSD, and should be scientifically examined as a potential treatment approach for PTSD, caution should be exerted with respect to the potential adverse effects that could be associated with excess, chronic cannabis use.

\section{CONCLUSIONS}

Here we described the biological findings associated with PTSD, the role of eCB signaling in these biological processes, and the impact cannabinoids have on these processes. Together, these data create an evidence-based rationale implicating the eCB system as a potential candidate system, whose impairment could be a substrate for the etiology of PTSD, as well as a target for the development of a novel class 
of drugs that could be used to treat symptoms of PTSD. The overall picture that emerges from this summary is that disturbances in neuronal, hormonal, and inflammatory systems that have been found in PTSD, and are believed to subserve the genesis of this disease, are all potentially modifiable by $\mathrm{eCB}$ signaling and exogenous cannabis products. However, there remains a critical need for highquality research focused on determining the clinical efficacy of eCB modulation and cannabis-related products in the treatment and course of PTSD.

\section{FUNDING AND DISCLOSURE}

The writers of this work were supported by NIH grants MH100096 and MH107435 (SP) and operating funds from the Canadian Institutes of Health Research (CIHR). MNH is the recipient of salary support from a Tier II Canada Research Chair from CIHR. SP has an active research contract with Lundbeck $\mathrm{A} / \mathrm{S}$ pharmaceuticals. $\mathrm{MNH}$ receives consulting fees from both Pfizer International and GW Pharmaceuticals and has unrestricted operating funds from GW that is for a project unrelated to anything discussed in this review. The remaining authors declare no conflict of interest.

\section{REFERENCES}

Abush H, Akirav I (2010). Cannabinoids modulate hippocampal memory and plasticity. Hippocampus 20: 1126-1138.

Aerni A, Traber R, Hock C, Roozendaal B, Schelling G, Papassotiropoulos A et al (2004). Low-dose cortisol for symptoms of posttraumatic stress disorder. Am J Psychiatry 161: 1488-1490.

Aggarwal SK, Carter GT, Sullivan MD, ZumBrunnen C, Morrill R, Mayer JD (2009). Medicinal use of cannabis in the United States: historical perspectives, current trends, and future directions. J Opioid Manag 5: 153-168.

Ahn K, McKinney MK, Cravatt BF (2008). Enzymatic pathways that regulate endocannabinoid signaling in the nervous system. Chem Rev 108: 1687-1707.

Alhouayek M, Lambert DM, Delzenne NM, Cani PD, Muccioli GG (2011). Increasing endogenous 2-arachidonoylglycerol levels counteracts colitis and related systemic inflammation. FASEB J 25: 2711-2721.

Almeida-Santos AF, Gobira PH, Rosa LC, Guimaraes FS, Moreira FA, Aguiar DC (2013). Modulation of anxiety-like behavior by the endocannabinoid 2-arachidonoylglycerol (2-AG) in the dorsolateral periaqueductal gray. Behav Brain Res 252: 10-17.

Almli LM, Fani N, Smith AK, Ressler KJ (2014). Genetic approaches to understanding post-traumatic stress disorder. Int $J$ Neuropsychopharmacol 17: 355-370.

APA. Diagnostic and Statistical Manual of Mental Disorders, 5th edn. American Psychiatric Association: Washington, DC, USA, 2013.

Atsak P, Hauer D, Campolongo P, Schelling G, McGaugh JL, Roozendaal B (2012). Glucocorticoids interact with the hippocampal endocannabinoid system in impairing retrieval of contextual fear memory. Proc Natl Acad Sci USA 109: 3504-3509.

Atwood BK, Mackie K (2010). CB2: a cannabinoid receptor with an identity crisis. Br J Pharmacol 160: 467-479.

Auclair N, Otani S, Soubrie P, Crepel F (2000). Cannabinoids modulate synaptic strength and plasticity at glutamatergic synapses of rat prefrontal cortex pyramidal neurons. J Neurophysiol 83: 3287-3293.

Azad SC, Eder M, Marsicano G, Lutz B, Zieglgansberger W, Rammes G (2003). Activation of the cannabinoid receptor type 1 decreases glutamatergic and GABAergic synaptic transmission in the lateral amygdala of the mouse. Learn Mem 10: 116-128

Balsevich G, Petrie GN, Hill MN (2017). Endocannabinoids: Effectors of glucocorticoid signaling. Front Neuroendocrinol (doi:10.1016/j.yfrne.2017.07.005).

Barna I, Csabai K, Makara GB, Zelena D (2009). Cannabinoid-mediated regulation of the hypothalamo-pituitary-adrenal axis in rats: age dependent role of vasopressin. Endocr Regul 43: 13-21.
Barna I, Zelena D, Arszovszki AC, Ledent C (2004). The role of endogenous cannabinoids in the hypothalamo-pituitary-adrenal axis regulation: in vivo and in vitro studies in CB1 receptor knockout mice. Life Sci 75: 2959-2970.

Batkai S, Osei-Hyiaman D, Pan H, El-Assal O, Rajesh M, Mukhopadhyay P et al (2007). Cannabinoid-2 receptor mediates protection against hepatic ischemia/ reperfusion injury. FASEB J 21: 1788-1800.

Bedse G, Colangeli R, Lavecchia AM, Romano A, Altieri F, Cifani C et al (2014). Role of the basolateral amygdala in mediating the effects of the fatty acid amide hydrolase inhibitor URB597 on HPA axis response to stress. Eur Neuropsychopharmacol 24: 1511-1523.

Bedse G, Hartley ND, Neale E, Gaulden AD, Patrick TA, Kingsley PJ et al (2017). Functional redundancy between canonical endocannabinoid signaling systems in the modulation of anxiety. Biol Psychiatry (doi:10.1016/j.biopsych.2017.03.002; e-pub ahead of print).

Bellocchio L, Soria-Gomez E, Quarta C, Metna-Laurent M, Cardinal P, Binder E et al (2013). Activation of the sympathetic nervous system mediates hypophagic and anxiety-like effects of $\mathrm{CB}(1)$ receptor blockade. Proc Natl Acad Sci USA 110: 4786-4791.

Benowitz NL, Jones RT (1977). Prolonged delta-9-tetrahydrocannabinol ingestion. Effects of sympathomimetic amines and autonomic blockades. Clin Pharmacol Ther 21: 336-342.

Betthauser K, Pilz J, Vollmer LE (2015). Use and effects of cannabinoids in military veterans with posttraumatic stress disorder. Am J Health Syst Pharm 72: 1279-1284.

Bi Q, Shi L, Yang P, Wang J, Qin L (2016). Minocycline attenuates interferon-alphainduced impairments in rat fear extinction. J Neuroinflammation 13: 172.

Binder EB (2009). The role of FKBP5, a co-chaperone of the glucocorticoid receptor in the pathogenesis and therapy of affective and anxiety disorders. Psychoneuroendocrinology 34(Suppl 1): S186-S195.

Binder EB, Bradley RG, Liu W, Epstein MP, Deveau TC, Mercer KB et al (2008). Association of FKBP5 polymorphisms and childhood abuse with risk of posttraumatic stress disorder symptoms in adults. JAMA 299: 1291-1305.

Bitencourt RM, Pamplona FA, Takahashi RN (2014). Corticosteroid-endocannabinoid loop supports decrease of fear-conditioned response in rats. Eur Neuropsychopharmacol 24: 1091-1102.

Blankman JL, Cravatt BF (2013). Chemical probes of endocannabinoid metabolism. Pharmacol Rev 65: 849-871.

Blasio A, Rice KC, Sabino V, Cottone P (2014). Characterization of a shortened model of diet alternation in female rats: effects of the CB1 receptor antagonist rimonabant on food intake and anxiety-like behavior. Behav Pharmacol 25: 609-617.

Blessing EM, Steenkamp MM, Manzanares J, Marmar CR (2015). Cannabidiol as a potential treatment for anxiety disorders. Neurotherapeutics 12: 825-836.

Bluett RJ, Baldi R, Haymer A, Gaulden AD, Hartley ND, Parrish WP et al (2017). Endocannabinoid signalling modulates susceptibility to traumatic stress exposure. Nat Commun 8: 14782.

Bluett RJ, Gamble-George JC, Hermanson DJ, Hartley ND, Marnett LJ, Patel S (2014). Central anandamide deficiency predicts stress-induced anxiety: behavioral reversal through endocannabinoid augmentation. Transl Psychiatry 4: e408.

Boden MT, Babson KA, Vujanovic AA, Short NA, Bonn-Miller MO (2013). Posttraumatic stress disorder and cannabis use characteristics among military veterans with cannabis dependence. Am J Addict 22: 277-284.

Bonn-Miller MO, Vujanovic AA, Feldner MT, Bernstein A, Zvolensky MJ (2007a). Posttraumatic stress symptom severity predicts marijuana use coping motives among traumatic event-exposed marijuana users. J Trauma Stress 20: 577-586.

Bonn-Miller MO, Zvolensky MJ, Bernstein A (2007b). Marijuana use motives: concurrent relations to frequency of past 30-day use and anxiety sensitivity among young adult marijuana smokers. Addict Behav 32: 49-62.

Boorman E, Zajkowska Z, Ahmed R, Pariante CM, Zunszain PA (2016). Crosstalk between endocannabinoid and immune systems: a potential dysregulation in depression? Psychopharmacology 233: 1591-1604.

Bortolato M, Campolongo P, Mangieri RA, Scattoni ML, Frau R, Trezza V et al (2006). Anxiolytic-like properties of the anandamide transport inhibitor AM404. Neuropsychopharmacology 31: 2652-2659.

Bosch-Bouju C, Larrieu T, Linders L, Manzoni OJ, Laye S (2016). Endocannabinoidmediated plasticity in nucleus accumbens controls vulnerability to anxiety after social defeat stress. Cell Rep 16: 1237-1242.

Bowens N, Heydendael W, Bhatnagar S, Jacobson L (2012). Lack of elevations in glucocorticoids correlates with dysphoria-like behavior after repeated social defeat. Physiol Behav 105: 958-965.

Bowers ME, Ressler KJ (2015a). Interaction between the cholecystokinin and endogenous cannabinoid systems in cued fear expression and extinction retention. Neuropsychopharmacology 40: 688-700.

Bowers ME, Ressler KJ (2015b). An overview of translationally informed treatments for posttraumatic stress disorder: animal models of Pavlovian fear conditioning to human clinical trials. Biol Psychiatry 78: E15-E27. 
Bowers ME, Ressler KJ (2016). Sex-dependence of anxiety-like behavior in cannabinoid receptor 1 (Cnr1) knockout mice. Behav Brain Res 300: 65-69.

Bowles NP, Karatsoreos IN, Li X, Vemuri VK, Wood JA, Li Z et al (2015). A peripheral endocannabinoid mechanism contributes to glucocorticoid-mediated metabolic syndrome. Proc Natl Acad Sci USA 112: 285-290.

Breen MS, Maihofer AX, Glatt SJ, Tylee DS, Chandler SD, Tsuang MT et al (2015). Gene networks specific for innate immunity define post-traumatic stress disorder. Mol Psychiatry 20: 1538-1545.

Bremner JD, Southwick SM, Darnell A, Charney DS (1996). Chronic PTSD in Vietnam combat veterans: course of illness and substance abuse. Am $J$ Psychiatry 153: 369-375.

Bucherelli C, Baldi E, Mariottini C, Passani MB, Blandina P (2006). Aversive memory reactivation engages in the amygdala only some neurotransmitters involved in consolidation. Learn Mem 13: 426-430.

Buckner JD, Schmidt NB, Bobadilla L, Taylor J (2006). Social anxiety and problematic cannabis use: evaluating the moderating role of stress reactivity and perceived coping. Behav Res Ther 44: 1007-1015.

Buckner JD, Zvolensky MJ (2014). Cannabis and related impairment: the unique roles of cannabis use to cope with social anxiety and social avoidance. Am J Addict 23: 598-603.

Buckner JD, Zvolensky MJ, Schmidt NB (2012). Cannabis-related impairment and social anxiety: the roles of gender and cannabis use motives. Addict Behav 37: 1294-1297.

Bujarski SJ, Feldner MT, Lewis SF, Babson KA, Trainor CD, Leen-Feldner E et al (2012). Marijuana use among traumatic event-exposed adolescents: posttraumatic stress symptom frequency predicts coping motivations for use. Addict Behav 37: 53-59.

Burman MA, Szolusha K, Bind R, Kerney K, Boger DL, Bilsky EJ (2016). FAAH inhibitor OL-135 disrupts contextual, but not auditory, fear conditioning in rats. Behav Brain Res 308: 1-5.

Busquets-Garcia A, Bains JS, Marsicano G (2017). CB1 receptors signaling in the brain: extracting specificity from ubiquity. Neuropsychopharmacology (e-pub ahead of print).

Busquets-Garcia A, Puighermanal E, Pastor A, de la Torre R, Maldonado R, Ozaita A (2011). Differential role of anandamide and 2-arachidonoylglycerol in memory and anxiety-like responses. Biol Psychiatry 70: 479-486.

Cameron C, Watson D, Robinson J (2014). Use of a synthetic cannabinoid in a correctional population for posttraumatic stress disorder-related insomnia and nightmares, chronic pain, harm reduction, and other indications: a retrospective evaluation. J Clin Psychopharmacol 34: 559-564.

Campolongo P, Roozendaal B, Trezza V, Hauer D, Schelling G, McGaugh JL et al (2009). Endocannabinoids in the rat basolateral amygdala enhance memory consolidation and enable glucocorticoid modulation of memory. Proc Natl Acad Sci USA 106: 4888-4893.

Campos AC, Ferreira FR, Guimaraes FS, Lemos Jl (2010). Facilitation of endocannabinoid effects in the ventral hippocampus modulates anxiety-like behaviors depending on previous stress experience. Neuroscience 167: 238-246.

Careaga MB, Girardi CE, Suchecki D (2016). Understanding posttraumatic stress disorder through fear conditioning, extinction and reconsolidation. Neurosci Biobehav Rev 71: 48-57.

Carrier EJ, Auchampach JA, Hillard CJ (2006). Inhibition of an equilibrative nucleoside transporter by cannabidiol: a mechanism of cannabinoid immunosuppression. Proc Natl Acad Sci USA 103: 7895-7900.

Ceccarini J, Kuepper R, Kemels D, van Os J, Henquet C, Van Laere K (2015). [18F] MK-9470 PET measurement of cannabinoid CB1 receptor availability in chronic cannabis users. Addict Biol 20: 357-367.

Chen J, Song Y, Yang J, Zhang Y, Zhao P, Zhu XJ et al (2013). The contribution of TNF-alpha in the amygdala to anxiety in mice with persistent inflammatory pain. Neurosci Lett 541: 275-280.

Chhatwal JP, Gutman AR, Maguschak KA, Bowser ME, Yang Y, Davis M et al (2009). Functional interactions between endocannabinoid and CCK neurotransmitter systems may be critical for extinction learning. Neuropsychopharmacology 34: 509-521.

Chiang KP, Gerber AL, Sipe JC, Cravatt BF (2004). Reduced cellular expression and activity of the P129T mutant of human fatty acid amide hydrolase: evidence for a link between defects in the endocannabinoid system and problem drug use. Hum Mol Genet 13: 2113-2119.

Chiu CQ, Puente N, Grandes P, Castillo PE (2010). Dopaminergic modulation of endocannabinoid-mediated plasticity at GABAergic synapses in the prefrontal cortex. J Neurosci 30: 7236-7248.

Chiurchiu V, Leuti A, Maccarrone M (2015). Cannabinoid signaling and neuroinflammatory diseases: a melting pot for the regulation of brain immune responses. J Neuroimmune Pharmacol 10: 268-280.
Chouker A, Kaufmann I, Kreth S, Hauer D, Feuerecker M, Thieme D et al (2010). Motion sickness, stress and the endocannabinoid system. PLOS ONE 5: e10752. Christensen R, Kristensen PK, Bartels EM, Bliddal H, Astrup A (2007). Efficacy and safety of the weight-loss drug rimonabant: a meta-analysis of randomised trials. Lancet 370: 1706-1713.

Cornelius JR, Aizenstein HJ, Hariri AR (2010). Amygdala reactivity is inversely related to level of cannabis use in individuals with comorbid cannabis dependence and major depression. Addict Behav 35: 644-646.

Cota D, Steiner MA, Marsicano G, Cervino C, Herman JP, Grubler Y et al (2007). Requirement of cannabinoid receptor type 1 for the basal modulation of hypothalamic-pituitary-adrenal axis function. Endocrinology 148: 1574-1581.

Cougle JR, Bonn-Miller MO, Vujanovic AA, Zvolensky MJ, Hawkins KA (2011). Posttraumatic stress disorder and cannabis use in a nationally representative sample. Psychol Addict Behav 25: 554-558.

Das RK, Kamboj SK, Ramadas M, Yogan K, Gupta V, Redman E et al (2013). Cannabidiol enhances consolidation of explicit fear extinction in humans. Psychopharmacology 226: 781-792.

Daskalakis NP, Lehrner A, Yehuda R (2013). Endocrine aspects of post-traumatic stress disorder and implications for diagnosis and treatment. Endocrinol Metab Clin North Am 42: 503-513.

de Bitencourt RM, Pamplona FA, Takahashi RN (2013). A current overview of cannabinoids and glucocorticoids in facilitating extinction of aversive memories: potential extinction enhancers. Neuropharmacology 64: 389-395.

de Oliveira Alvares L, Engelke DS, Diehl F, Scheffer-Teixeira R, Haubrich J, de Freitas Cassini L et al (2010). Stress response recruits the hippocampal endocannabinoid system for the modulation of fear memory. Learn Mem 17: 202-209.

de Oliveira Alvares L, Pasqualini Genro B, Diehl F, Molina VA, Quillfeldt JA (2008). Opposite action of hippocampal CB1 receptors in memory reconsolidation and extinction. Neuroscience 154: 1648-1655.

Degroot A, Nomikos GG (2004). Genetic deletion and pharmacological blockade of CB1 receptors modulates anxiety in the shock-probe burying test. Eur $J$ Neurosci 20: 1059-1064.

Demers CH, Drabant Conley E, Bogdan R, Hariri AR (2016). Interactions between anandamide and corticotropin-releasing factor signaling modulate human amygdala function and risk for anxiety disorders: an imaging genetics strategy for modeling molecular interactions. Biol Psychiatry 80: 356-362.

Devane WA, Hanus L, Breuer A, Pertwee RG, Stevenson LA, Griffin G et al (1992). Isolation and structure of a brain constituent that binds to the cannabinoid receptor. Science 258: 1946-1949.

Di S, Itoga CA, Fisher MO, Solomonow J, Roltsch EA, Gilpin NW et al (2016). Acute stress suppresses synaptic inhibition and increases anxiety via endocannabinoid release in the basolateral amygdala. J Neurosci 36: 8461-8470.

Di S, Malcher-Lopes R, Marcheselli VL, Bazan NG, Tasker JG (2005). Rapid glucocorticoid-mediated endocannabinoid release and opposing regulation of glutamate and gamma-aminobutyric acid inputs to hypothalamic magnocellular neurons. Endocrinology 146: 4292-4301.

Diamond DM, Zoladz PR (2016). Dysfunctional or hyperfunctional? The amygdala in posttraumatic stress disorder is the bull in the evolutionary China shop. $J$ Neurosci Res 94: 437-444.

Dincheva I, Drysdale AT, Hartley CA, Johnson DC, Jing D, King EC et al (2015). FAAH genetic variation enhances fronto-amygdala function in mouse and human. Nat Commun 6: 6395.

Dlugos A, Childs E, Stuhr KL, Hillard CJ, de Wit H (2012). Acute stress increases circulating anandamide and other $\mathrm{N}$-acylethanolamines in healthy humans. Neuropsychopharmacology 37: 2416-2427.

Domenici MR, Azad SC, Marsicano G, Schierloh A, Wotjak CT, Dodt HU et al (2006). Cannabinoid receptor type 1 located on presynaptic terminals of principal neurons in the forebrain controls glutamatergic synaptic transmission. $J$ Neurosci 26: $5794-5799$.

Draycott B, Loureiro M, Ahmad T, Tan H, Zunder J, Laviolette SR (2014). Cannabinoid transmission in the prefrontal cortex bi-phasically controls emotional memory formation via functional interactions with the ventral tegmental area. J Neurosci 34: 13096-13109.

Duan T, Gu N, Wang Y, Wang F, Zhu J, Fang $Y$ et al (2016). Fatty acid amide hydrolase inhibitors produce rapid anti-anxiety responses through amygdala longterm depression in male rodents. J Psychiatry Neurosci 42: 160116.

Dubreucq S, Matias I, Cardinal P, Haring M, Lutz B, Marsicano G et al (2012). Genetic dissection of the role of cannabinoid type-1 receptors in the emotional consequences of repeated social stress in mice. Neuropsychopharmacology 37: 1885-1900.

Duvarci S, Pare D (2014). Amygdala microcircuits controlling learned fear. Neuron 82: 966-980.

Engler H, Doenlen R, Engler A, Riether C, Prager G, Niemi MB et al (2011). Acute amygdaloid response to systemic inflammation. Brain Behav Immun 25: 1384-1392. 
Evanson NK, Tasker JG, Hill MN, Hillard CJ, Herman JP (2010). Fast feedback inhibition of the HPA axis by glucocorticoids is mediated by endocannabinoid signaling. Endocrinology 151: 4811-4819.

Fabre LF, McLendon D (1981). The efficacy and safety of Nabilone (a synthetic cannabinoid) in the treatment of anxiety. J Clin Pharmacol 21(8-9 Suppl): 377S-382S.

Feinberg I, Jones R, Walker J, Cavness C, Floyd T (1976). Effects of marijuana extract and tetrahydrocannabinol on electroencephalographic sleep patterns. Clin Pharmacol Ther 19: 782-794.

Feinberg I, Jones R, Walker JM, Cavness C, March J (1975). Effects of high dosage delta-9-tetrahydrocannabinol on sleep patterns in man. Clin Pharmacol Ther 17: 458-466.

Fortin DA, Levine ES (2007). Differential effects of endocannabinoids on glutamatergic and GABAergic inputs to layer 5 pyramidal neurons. Cereb Cortex 17: 163-174.

Fraser GA (2009). The use of a synthetic cannabinoid in the management of treatment-resistant nightmares in posttraumatic stress disorder (PTSD). CNS Neurosci Ther 15: 84-88.

Fride E, Suris R, Weidenfeld J, Mechoulam R (2005). Differential response to acute and repeated stress in cannabinoid CB1 receptor knockout newborn and adult mice. Behav Pharmacol 16: 431-440.

Gamble-George JC, Baldi R, Halladay L, Kocharian A, Hartley N, Silva CG et al (2016). Cyclooxygenase-2 inhibition reduces stress-induced affective pathology. Elife 5: 1-20.

Gamble-George JC, Conger JR, Hartley ND, Gupta P, Sumislawski JJ, Patel S (2013). Dissociable effects of CB1 receptor blockade on anxiety-like and consummatory behaviors in the novelty-induced hypophagia test in mice. Psychopharmacology 228: 401-409.

Ganon-Elazar E, Akirav I (2009). Cannabinoid receptor activation in the basolateral amygdala blocks the effects of stress on the conditioning and extinction of inhibitory avoidance. J Neurosci 29: 11078-11088.

Ganon-Elazar E, Akirav I (2012). Cannabinoids prevent the development of behavioral and endocrine alterations in a rat model of intense stress. Neuropsychopharmacology 37: 456-466.

Gee DG, Fetcho RN, Jing D, Li A, Glatt CE, Drysdale AT et al (2016). Individual differences in frontolimbic circuitry and anxiety emerge with adolescent changes in endocannabinoid signaling across species. Proc Natl Acad Sci USA 113: 4500-4505.

Gilmartin MR, Balderston NL, Helmstetter FJ (2014). Prefrontal cortical regulation of fear learning. Trends Neurosci 37: 455-464.

Gorka SM, Fitzgerald DA, de Wit H, Phan KL (2014). Cannabinoid modulation of amygdala subregion functional connectivity to social signals of threat. Int $J$ Neuropsychopharmacol 18: 3.

Grabner GF, Eichmann TO, Wagner B, Gao Y, Farzi A, Taschler U et al (2016). Deletion of monoglyceride lipase in astrocytes attenuates lipopolysaccharideinduced neuroinflammation. J Biol Chem 291: 913-923.

Gray JM, Vecchiarelli HA, Morena M, Lee TT, Hermanson DJ, Kim AB et al (2015). Corticotropin-releasing hormone drives anandamide hydrolysis in the amygdala to promote anxiety. J Neurosci 35: 3879-3892.

Gray JM, Wilson CD, Lee TT, Pittman QJ, Deussing JM, Hillard CJ et al (2016). Sustained glucocorticoid exposure recruits cortico-limbic $\mathrm{CRH}$ signaling to modulate endocannabinoid function. Psychoneuroendocrinology 66: 151-158.

Griebel G, Stemmelin J, Scatton B (2005). Effects of the cannabinoid CB1 receptor antagonist rimonabant in models of emotional reactivity in rodents. Biol Psychiatry 57: 261-267.

Gruber SA, Rogowska J, Yurgelun-Todd DA (2009). Altered affective response in marijuana smokers: an FMRI study. Drug Alcohol Depend 105: 139-153.

Guggenhuber S, Romo-Parra H, Bindila L, Leschik J, Lomazzo E, Remmers F et al (2015). Impaired 2-AG signaling in hippocampal glutamatergic neurons: aggravation of anxiety-like behavior and unaltered seizure susceptibility. Int $J$ Neuropsychopharmacol 19: 1-20.

Gunduz-Cinar O, Flynn S, Brockway E, Kaugars K, Baldi R, Ramikie TS et al (2016). Fluoxetine facilitates fear extinction through amygdala endocannabinoids. Neuropsychopharmacology 41: 1598-1609.

Gunduz-Cinar O, Hill MN, McEwen BS, Holmes A (2013a). Amygdala FAAH and anandamide: mediating protection and recovery from stress. Trends Pharmacol Sci 34: 637-644.

Gunduz-Cinar O, MacPherson KP, Cinar R, Gamble-George J, Sugden K, Williams $\mathrm{B}$ et al (2013b). Convergent translational evidence of a role for anandamide in amygdala-mediated fear extinction, threat processing and stress-reactivity. Mol Psychiatry 18: 813-823.

Halikas JA, Goodwin DW, Guze SB (1971). Marihuana effects. A survey of regular users. JAMA 217: 692-694.
Haller J, Aliczki M, Pelczer KG, Spitzer K, Balogh Z, Kantor S (2014). Effects of the fatty acid amide hydrolase inhibitor URB597 on coping behavior under challenging conditions in mice. Psychopharmacology 231: 593-601.

Haller J, Barna I, Barsvari B, Gyimesi Pelczer K, Yasar S, Panlilio LV et al (2009). Interactions between environmental aversiveness and the anxiolytic effects of enhanced cannabinoid signaling by FAAH inhibition in rats. Psychopharmacology 204: 607-616.

Haller J, Goldberg SR, Pelczer KG, Aliczki M, Panlilio LV (2013). The effects of anandamide signaling enhanced by the FAAH inhibitor URB597 on coping styles in rats. Psychopharmacology 230: 353-362.

Haller J, Varga B, Ledent C, Freund TF (2004). CB1 cannabinoid receptors mediate anxiolytic effects: convergent genetic and pharmacological evidence with CB1-specific agents. Behav Pharmacol 15: 299-304.

Haring M, Enk V, Aparisi Rey A, Loch S, Ruiz de Azua I, Weber T et al (2015). Cannabinoid type-1 receptor signaling in central serotonergic neurons regulates anxiety-like behavior and sociability. Front Behav Neurosci 9: 235.

Hariri AR, Gorka A, Hyde LW, Kimak M, Halder I, Ducci F et al (2009). Divergent effects of genetic variation in endocannabinoid signaling on human threat- and reward-related brain function. Biol Psychiatry 66: 9-16.

Harris AZ, Gordon JA (2015). Long-range neural synchrony in behavior. Annu Rev Neurosci 38: 171-194.

Hartley ND, Gunduz-Cinar O, Halladay L, Bukalo O, Holmes A, Patel S (2016). 2-arachidonoylglycerol signaling impairs short-term fear extinction. Trans/ Psychiatry 6: e749.

Hauer D, Schelling G, Gola H, Campolongo P, Morath J, Roozendaal B et al (2013). Plasma concentrations of endocannabinoids and related primary fatty acid amides in patients with post-traumatic stress disorder. PLOS ONE 8: e62741.

Henckens MJ, van Wingen GA, Joels M, Fernandez G (2010). Time-dependent effects of corticosteroids on human amygdala processing. I Neurosci 30: 12725-12732.

Henckens MJ, van Wingen GA, Joels M, Fernandez G (2012). Corticosteroid induced decoupling of the amygdala in men. Cereb Cortex 22: 2336-2345.

Heng L, Beverley JA, Steiner H, Tseng KY (2011). Differential developmental trajectories for CB1 cannabinoid receptor expression in limbic/associative and sensorimotor cortical areas. Synapse 65: 278-286.

Hermanson DJ, Hartley ND, Gamble-George J, Brown N, Shonesy BC, Kingsley PJ et al (2013). Substrate-selective COX-2 inhibition decreases anxiety via endocannabinoid activation. Nat Neurosci 16: 1291-1298.

Hernangomez M, Mestre L, Correa FG, Loria F, Mecha M, Inigo PM et al (2012). CD200-CD200R1 interaction contributes to neuroprotective effects of anandamide on experimentally induced inflammation. Glia 60: 1437-1450.

Hill MN, Bierer LM, Makotkine I, Golier JA, Galea S, McEwen BS et al (2013a). Reductions in circulating endocannabinoid levels in individuals with post-traumatic stress disorder following exposure to the World Trade Center attacks. Psychoneuroendocrinology 38: 2952-2961.

Hill MN, Carrier EJ, McLaughlin RJ, Morrish AC, Meier SE, Hillard CJ et al (2008a). Regional alterations in the endocannabinoid system in an animal model of depression: effects of concurrent antidepressant treatment. I Neurochem 106: 2322-2336.

Hill MN, Gorzalka BB (2004). Enhancement of anxiety-like responsiveness to the cannabinoid $\mathrm{CB}(1)$ receptor agonist $\mathrm{HU}-210$ following chronic stress. Eur $J$ Pharmacol 499: 291-295.

Hill MN, Hillard CJ, McEwen BS (2011a). Alterations in corticolimbic dendritic morphology and emotional behavior in cannabinoid CB1 receptor-deficient mice parallel the effects of chronic stress. Cereb Cortex 21: 2056-2064.

Hill MN, Karacabeyli ES, Gorzalka BB (2007). Estrogen recruits the endocannabinoid system to modulate emotionality. Psychoneuroendocrinology 32: 350-357.

Hill MN, Karatsoreos IN, Hillard CJ, McEwen BS (2010a). Rapid elevations in limbic endocannabinoid content by glucocorticoid hormones in vivo. Psychoneuroendocrinology 35: 1333-1338.

Hill MN, Kumar SA, Filipski SB, Iverson M, Stuhr KL, Keith JM et al (2013b). Disruption of fatty acid amide hydrolase activity prevents the effects of chronic stress on anxiety and amygdalar microstructure. Mol Psychiatry 18: 1125-1135.

Hill MN, McEwen BS (2010b). Involvement of the endocannabinoid system in the neurobehavioural effects of stress and glucocorticoids. Prog Neuropsychopharmacol Biol Psychiatry 34: 791-797.

Hill MN, McLaughlin RJ, Bingham B, Shrestha L, Lee TT, Gray JM et al (2010c). Endogenous cannabinoid signaling is essential for stress adaptation. Proc Natl Acad Sci USA 107: 9406-9411.

Hill MN, McLaughlin RJ, Morrish AC, Viau V, Floresco SB, Hillard CJ et al (2009a). Suppression of amygdalar endocannabinoid signaling by stress contributes to activation of the hypothalamic-pituitary-adrenal axis. Neuropsychopharmacology 34: 2733-2745. 
Hill MN, McLaughlin RJ, Pan B, Fitzgerald ML, Roberts CJ, Lee TT et al (2011b). Recruitment of prefrontal cortical endocannabinoid signaling by glucocorticoids contributes to termination of the stress response. J Neurosci 31: 10506-10515.

Hill MN, Miller GE, Carrier EJ, Gorzalka BB, Hillard CJ (2009b). Circulating endocannabinoids and $\mathrm{N}$-acyl ethanolamines are differentially regulated in major depression and following exposure to social stress. Psychoneuroendocrinology 34: 1257-1262.

Hill MN, Miller GE, Ho WS, Gorzalka BB, Hillard CJ (2008b). Serum endocannabinoid content is altered in females with depressive disorders: a preliminary report. Pharmacopsychiatry 41: 48-53.

Hill MN, Patel S, Carrier EJ, Rademacher DJ, Ormerod BK, Hillard CJ et al (2005). Downregulation of endocannabinoid signaling in the hippocampus following chronic unpredictable stress. Neuropsychopharmacology 30: 508-515.

Hill MN, Tasker JG (2012). Endocannabinoid signaling, glucocorticoid-mediated negative feedback, and regulation of the hypothalamic-pituitary-adrenal axis. Neuroscience 204: 5-16.

Hillard CJ, Beatka M, Sarvaideo J (2016). Endocannabinoid signaling and the hypothalamic-pituitary-adrenal axis. Compr Physiol 7: 1-15.

Hirvonen J, Goodwin RS, Li CT, Terry GE, Zoghbi SS, Morse C et al (2012). Reversible and regionally selective downregulation of brain cannabinoid CB1 receptors in chronic daily cannabis smokers. Mol Psychiatry 17: 642-649.

Horn SR, Charney DS, Feder A (2016). Understanding resilience: new approaches for preventing and treating PTSD. Exp Neurol 284(Pt B): 119-132.

Hoskins M, Pearce J, Bethell A, Dankova L, Barbui C, Tol WA et al (2015). Pharmacotherapy for post-traumatic stress disorder: systematic review and meta-analysis. Br J Psychiatry 206: 93-100.

Howlett AC (2002). The cannabinoid receptors. Prostaglandins Other Lipid Mediat 68-69: 619-631.

Hughes KC, Shin LM (2011). Functional neuroimaging studies of post-traumatic stress disorder. Expert Rev Neurother 11: 275-285.

Huitron-Resendiz S, Sanchez-Alavez M, Wills DN, Cravatt BF, Henriksen SJ (2004). Characterization of the sleep-wake patterns in mice lacking fatty acid amide hydrolase. Sleep 27: 857-865.

Inagaki TK, Muscatell KA, Irwin MR, Cole SW, Eisenberger NI (2012). Inflammation selectively enhances amygdala activity to socially threatening images. Neuroimage 59: 3222-3226.

Ishac EJ, Jiang L, Lake KD, Varga K, Abood ME, Kunos G (1996). Inhibition of exocytotic noradrenaline release by presynaptic cannabinoid $\mathrm{CB} 1$ receptors on peripheral sympathetic nerves. Br J Pharmacol 118: 2023-2028.

Izzo AA, Borrelli F, Capasso R, Di Marzo V, Mechoulam R (2009). Non-psychotropic plant cannabinoids: new therapeutic opportunities from an ancient herb. Trends Pharmacol Sci 30: 515-527.

Jacobs JA, Dellarco AJ, Manfredi RA, Harclerode J (1979). The effects of delta 9-tetrahydrocannabinol, cannabidiol, and shock on plasma corticosterone concentrations in rats. J Pharm Pharmacol 31: 341-342.

Jamali-Raeufy N, Nasehi M, Ebrahimi-Ghiri M, Zarrindast MR (2011). Cross statedependency of learning between WIN55, 212-2 and scopolamine in rat dorsal hippocampus. Neurosci Lett 491: 227-231.

Janak PH, Tye KM (2015). From circuits to behaviour in the amygdala. Nature 517: 284-292.

Jenniches I, Ternes S, Albayram O, Otte DM, Bach K, Bindila L et al (2016). Anxiety, stress, and fear response in mice with reduced endocannabinoid levels. Biol Psychiatry 79: 858-868.

Jennings EM, Okine BN, Olango WM, Roche M, Finn DP (2016). Repeated forced swim stress differentially affects formalin-evoked nociceptive behaviour and the endocannabinoid system in stress normo-responsive and stress hyperresponsive rat strains. Prog Neuropsychopharmacol Biol Psychiatry 64: 181-189.

Jetly R, Heber A, Fraser G, Boisvert D (2015). The efficacy of Nabilone, a synthetic cannabinoid, in the treatment of PTSD-associated nightmares: a preliminary randomized, double-blind, placebo-controlled cross-over design study. Psychoneuroendocrinology 51: 585-588,

Ji G, Neugebauer V (2014). CB1 augments mGluR5 function in medial prefrontal cortical neurons to inhibit amygdala hyperactivity in an arthritis pain model. Eur J Neurosci 39: 455-466.

Jiang SK, Zhang M, Tian ZL, Wang M, Zhao R, Wang LL et al (2015). The monoacylglycerol lipase inhibitor JZL184 decreases inflammatory response in skeletal muscle contusion in rats. Eur J Pharmacol 761: 1-10.

Joels M, Fernandez G, Roozendaal B (2011). Stress and emotional memory: a matter of timing. Trends Cogn Sci 15: 280-288.

Johnson KM, Dewey WL, Ritter KS, Beckner JS (1978). Cannabinoid effects on plasma corticosterone and uptake of $3 \mathrm{H}$-corticosterone by mouse brain. Eur $\mathrm{J}$ Pharmacol 47: 303-310.
Jurkus R, Day HL, Guimaraes FS, Lee JL, Bertoglio LJ, Stevenson CW (2016). Cannabidiol regulation of learned fear: implications for treating anxiety-related disorders. Front Pharmacol 7: 454.

Kamprath K, Marsicano G, Tang J, Monory K, Bisogno T, Di Marzo V et al (2006). Cannabinoid $\mathrm{CB} 1$ receptor mediates fear extinction via habituation-like processes. J Neurosci 26: 6677-6686.

Kamprath K, Plendl W, Marsicano G, Deussing JM, Wurst W, Lutz B et al (2009). Endocannabinoids mediate acute fear adaptation via glutamatergic neurons independently of corticotropin-releasing hormone signaling. Genes Brain Behav 8: 203-211.

Karst H, Berger S, Erdmann G, Schutz G, Joels M (2010). Metaplasticity of amygdalar responses to the stress hormone corticosterone. Proc Natl Acad Sci USA 107: 14449-14454.

Kathuria S, Gaetani S, Fegley D, Valino F, Duranti A, Tontini A et al (2003). Modulation of anxiety through blockade of anandamide hydrolysis. Nat Med $\mathbf{9}$ : 76-81.

Katona I, Freund TF (2012). Multiple functions of endocannabinoid signaling in the brain. Annu Rev Neurosci 35: 529-558.

Katona I, Rancz EA, Acsady L, Ledent C, Mackie K, Hajos N et al (2001). Distribution of $\mathrm{CB} 1$ cannabinoid receptors in the amygdala and their role in the control of GABAergic transmission. J Neurosci 21: 9506-9518.

Katz D, Katz I, Porat-Katz BS, Shoenfeld Y (2017). Medical cannabis: another piece in the mosaic of autoimmunity? Clin Pharmacol Ther 101: 230-238.

Kelmendi B, Adams TG, Yarnell S, Southwick S, Abdallah CG, Krystal JH (2016). PTSD: from neurobiology to pharmacological treatments. Eur J Psychotraumatol 7: 31858.

Kerr DM, Burke NN, Ford GK, Connor TJ, Harhen B, Egan LJ et al (2012). Pharmacological inhibition of endocannabinoid degradation modulates the expression of inflammatory mediators in the hypothalamus following an immunological stressor. Neuroscience 204: 53-63.

Kerr DM, Harhen B, Okine BN, Egan LJ, Finn DP, Roche M (2013). The monoacylglycerol lipase inhibitor JZL184 attenuates LPS-induced increases in cytokine expression in the rat frontal cortex and plasma: differential mechanisms of action. Br J Pharmacol 169: 808-819.

Kilpatrick DG, Resnick HS, Milanak ME, Miller MW, Keyes KM, Friedman MJ (2013). National estimates of exposure to traumatic events and PTSD prevalence using DSM-IV and DSM-5 criteria. J Trauma Stress 26: 537-547.

Kim MJ, Loucks RA, Palmer AL, Brown AC, Solomon KM, Marchante AN et al (2011). The structural and functional connectivity of the amygdala: from normal emotion to pathological anxiety. Behav Brain Res 223: 403-410.

Kinsey SG, O'Neal ST, Long JZ, Cravatt BF, Lichtman AH (2011). Inhibition of endocannabinoid catabolic enzymes elicits anxiolytic-like effects in the marble burying assay. Pharmacol Biochem Behav 98: 21-27.

Kiritoshi T, Ji G, Neugebauer $\vee$ (2016). Rescue of impaired mGluR5-driven endocannabinoid signaling restores prefrontal cortical output to inhibit pain in arthritic rats. J Neurosci 36: 837-850.

Klengel T, Mehta D, Anacker C, Rex-Haffner M, Pruessner JC, Pariante CM et al (2013). Allele-specific FKBP5 DNA demethylation mediates gene-childhood trauma interactions. Nat Neurosci 16: 33-41.

Kodirov SA, Jasiewicz J, Amirmahani P, Psyrakis D, Bonni K, Wehrmeister M et al (2010). Endogenous cannabinoids trigger the depolarization-induced suppression of excitation in the lateral amygdala. Learn Mem 17: 43-49.

Koenen KC, Ratanatharathorn A, Ng L, McLaughlin KA, Bromet EJ, Stein DJ et al (2017). Posttraumatic stress disorder in the World Mental Health Surveys. Psychol Med (e-pub ahead of print).

Komaki A, Abdollahzadeh F, Sarihi A, Shahidi S, Salehi I (2014). Interaction between antagonist of cannabinoid receptor and antagonist of adrenergic receptor on anxiety in male rat. Basic Clin Neurosci 5: 218-224.

Krishnan V, Han MH, Graham DL, Berton O, Renthal W, Russo SJ et al (2007). Molecular adaptations underlying susceptibility and resistance to social defeat in brain reward regions. Cell 131: 391-404.

Krystal JH, Neumeister A (2009). Noradrenergic and serotonergic mechanisms in the neurobiology of posttraumatic stress disorder and resilience. Brain Res 1293: 13-23.

Kuhnert S, Meyer C, Koch M (2013). Involvement of cannabinoid receptors in the amygdala and prefrontal cortex of rats in fear learning, consolidation, retrieval and extinction. Behav Brain Res 250: 274-284.

Lanius RA, Vermetten E, Loewenstein RJ, Brand B, Schmahl C, Bremner JD et al (2010). Emotion modulation in PTSD: clinical and neurobiological evidence for a dissociative subtype. Am J Psychiatry 167: 640-647.

Laricchiuta D, Centonze D, Petrosini L (2013). Effects of endocannabinoid and endovanilloid systems on aversive memory extinction. Behav Brain Res 256: 101-107.

LeDoux J (2007). The amygdala. Curr Biol 17: R868-R874. 
Likhtik E, Paz R (2015). Amygdala-prefrontal interactions in (mal)adaptive learning. Trends Neurosci 38: 158-166.

Lin HC, Mao SC, Chen PS, Gean PW (2008). Chronic cannabinoid administration in vivo compromises extinction of fear memory. Learn Mem 15: 876-884.

Lin L, Yihao T, Zhou F, Yin N, Qiang T, Haowen Z et al (2017). Inflammatory regulation by driving microglial $\mathrm{M} 2$ polarization: neuroprotective effects of cannabinoid receptor-2 activation in intracerebral hemorrhage. Front Immunol 8: 112.

Lissek S, van Meurs B (2015). Learning models of PTSD: theoretical accounts and psychobiological evidence. Int J Psychophysiol 98(3 Pt 2): 594-605.

Litvin Y, Phan A, Hill MN, Pfaff DW, McEwen BS (2013). CB1 receptor signaling regulates social anxiety and memory. Genes Brain Behav 12: 479-489.

Llorente-Berzal A, Terzian AL, di Marzo V, Micale V, Viveros MP, Wotjak CT (2015). 2-AG promotes the expression of conditioned fear via cannabinoid receptor type 1 on GABAergic neurons. Psychopharmacology 232: 2811-2825.

Lomazzo E, Bindila L, Remmers F, Lerner R, Schwitter C, Hoheisel U et al (2015). Therapeutic potential of inhibitors of endocannabinoid degradation for the treatment of stress-related hyperalgesia in an animal model of chronic pain. Neuropsychopharmacology 40: 488-501.

Lutz B, Marsicano G, Maldonado R, Hillard CJ (2015). The endocannabinoid system in guarding against fear, anxiety and stress. Nat Rev Neurosci 16: 705-718.

Maccarrone M, Valverde O, Barbaccia ML, Castane A, Maldonado R, Ledent C et al (2002). Age-related changes of anandamide metabolism in CB1 cannabinoid receptor knockout mice: correlation with behaviour. Eur $J$ Neurosci 15: 1178-1186.

Malek N, Popiolek-Barczyk K, Mika J, Przewlocka B, Starowicz K (2015). Anandamide, acting via CB2 receptors, alleviates LPS-induced neuroinflammation in rat primary microglial cultures. Neural Plast 2015: 130639.

Manzanares J, Corchero J, Fuentes JA (1999). Opioid and cannabinoid receptormediated regulation of the increase in adrenocorticotropin hormone and corticosterone plasma concentrations induced by central administration of delta (9)-tetrahydrocannabinol in rats. Brain Res 839: 173-179.

Maresz K, Carrier EJ, Ponomarev ED, Hillard CJ, Dittel BN (2005). Modulation of the cannabinoid CB2 receptor in microglial cells in response to inflammatory stimuli. J Neurochem 95: 437-445

Maresz K, Pryce G, Ponomarev ED, Marsicano G, Croxford JL, Shriver LP et al (2007). Direct suppression of CNS autoimmune inflammation via the cannabinoid receptor $\mathrm{CB} 1$ on neurons and $\mathrm{CB} 2$ on autoreactive $\mathrm{T}$ cells. Nat Med 13: 492-497.

Marin S, Marco E, Biscaia M, Fernandez B, Rubio M, Guaza C et al (2003). Involvement of the kappa-opioid receptor in the anxiogenic-like effect of $\mathrm{CP}$ 55,940 in male rats. Pharmacol Biochem Behav 74: 649-656.

Marsicano G, Wotjak CT, Azad SC, Bisogno T, Rammes G, Cascio MG et al (2002). The endogenous cannabinoid system controls extinction of aversive memories. Nature 418: 530-534.

Martin M, Ledent C, Parmentier M, Maldonado R, Valverde O (2002). Involvement of CB1 cannabinoid receptors in emotional behaviour. Psychopharmacology 159: 379-387.

Mason JW, Giller EL, Kosten TR, Ostroff RB, Podd L (1986). Urinary free-cortisol levels in posttraumatic stress disorder patients. J Nerv Ment Dis 174: 145-149.

Matsuda LA, Lolait SJ, Brownstein MJ, Young AC, Bonner TI (1990). Structure of a cannabinoid receptor and functional expression of the cloned cDNA. Nature 346: 561-564.

Mayer TA, Matar MA, Kaplan Z, Zohar J, Cohen H (2014). Blunting of the HPA-axis underlies the lack of preventive efficacy of early post-stressor single-dose Delta-9tetrahydrocannabinol (THC). Pharmacol Biochem Behav 122: 307-318.

McCoy KL (2016). Interaction between cannabinoid system and toll-like receptors controls inflammation. Mediators Inflamm 2016: 5831315.

McFarlane AC, Lawrence-Wood E, Van Hooff M, Malhi GS, Yehuda R (2017). The need to take a staging approach to the biological mechanisms of PTSD and its treatment. Curr Psychiatry Rep 19: 10.

McLaughlin RJ, Hill MN, Gorzalka BB (2009). Monoaminergic neurotransmission contributes to cannabinoid-induced activation of the hypothalamic-pituitaryadrenal axis. Eur J Pharmacol 624: 71-76.

McLaughlin RJ, Hill MN, Gorzalka BB (2014). A critical role for prefrontocortical endocannabinoid signaling in the regulation of stress and emotional behavior. Neurosci Biobehav Rev 42: 116-131.

Mecha M, Feliu A, Carrillo-Salinas FJ, Rueda-Zubiaurre A, Ortega-Gutierrez S, de Sola RG et al (2015). Endocannabinoids drive the acquisition of an alternative phenotype in microglia. Brain Behav Immun 49: 233-245.

Mechoulam R, Fride E, Hanus L, Sheskin T, Bisogno T, Di Marzo V et al (1997). Anandamide may mediate sleep induction. Nature 389: 25-26.

Mechoulam R, Hanus LO, Pertwee R, Howlett AC (2014). Early phytocannabinoid chemistry to endocannabinoids and beyond. Nat Rev Neurosci 15: 757-764.
Mellman TA, Kulick-Bell R, Ashlock LE, Nolan B (1995). Sleep events among veterans with combat-related posttraumatic stress disorder. Am J Psychiatry 152 110-115.

Michopoulos V, Powers A, Gillespie CF, Ressler KJ, Jovanovic T (2017). Inflammation in fear- and anxiety-based disorders: PTSD, GAD, and beyond. Neuropsychopharmacology 42: 254-270.

Milad MR, Pitman RK, Ellis CB, Gold AL, Shin LM, Lasko NB et al (2009). Neurobiological basis of failure to recall extinction memory in posttraumatic stress disorder. Biol Psychiatry 66: 1075-1082.

Mishima K, Egashira N, Hirosawa N, Fujii M, Matsumoto Y, Iwasaki K et al (2001). Characteristics of learning and memory impairment induced by delta9-tetrahydrocannabinol in rats. Jpn J Pharmacol 87: 297-308.

Moise AM, Eisenstein SA, Astarita G, Piomelli D, Hohmann AG (2008). An endocannabinoid signaling system modulates anxiety-like behavior in male Syrian hamsters. Psychopharmacology 200: 333-346.

Molderings GJ, Likungu J, Gothert M (1999). Presynaptic cannabinoid and imidazoline receptors in the human heart and their potential relationship. Naunyn Schmiedebergs Arch Pharmacol 360: 157-164.

Moreira FA, Grieb M, Lutz B (2009). Central side-effects of therapies based on CB1 cannabinoid receptor agonists and antagonists: focus on anxiety and depression. Best Pract Res Clin Endocrinol Metab 23: 133-144.

Moreira FA, Kaiser N, Monory K, Lutz B (2008). Reduced anxiety-like behaviour induced by genetic and pharmacological inhibition of the endocannabinoiddegrading enzyme fatty acid amide hydrolase (FAAH) is mediated by CB1 receptors. Neuropharmacology 54: 141-150.

Moreira FA, Wotjak CT (2010). Cannabinoids and anxiety. Curr Top Behav Neurosci 2: 429-450.

Morena M, Campolongo P (2014a). The endocannabinoid system: an emotional buffer in the modulation of memory function. Neurobiol Learn Mem 112: 30-43.

Morena M, De Castro V, Gray JM, Palmery M, Trezza V, Roozendaal B et al (2015). Training-associated emotional arousal shapes endocannabinoid modulation of spatial memory retrieval in rats. J Neurosci 35: 13962-13974.

Morena M, Leitl KD, Vecchiarelli HA, Gray JM, Campolongo P, Hill MN (2016a). Emotional arousal state influences the ability of amygdalar endocannabinoid signaling to modulate anxiety. Neuropharmacology 111: 59-69.

Morena M, Patel S, Bains JS, Hill MN (2016b). Neurobiological interactions between stress and the endocannabinoid system. Neuropsychopharmacology 41: 80-102.

Morena M, Roozendaal B, Trezza V, Ratano P, Peloso A, Hauer D et al (2014b). Endogenous cannabinoid release within prefrontal-limbic pathways affects memory consolidation of emotional training. Proc Natl Acad Sci USA 111: 18333-18338.

Moshfegh A, Babaei P, Oryan S, Soltani B, Zarrindast MR (2011). Involvement of dorsal hippocampal alpha1-adrenergic receptors in the effect of WIN55,212-2 on memory retrieval in inhibitory avoidance task. Neurosci Lett 489: 69-73.

Munro S, Thomas KL, Abu-Shaar M (1993). Molecular characterization of a peripheral receptor for cannabinoids. Nature 365: 61-65.

Murillo-Rodriguez E, Blanco-Centurion C, Sanchez C, Piomelli D, Shiromani PJ (2003). Anandamide enhances extracellular levels of adenosine and induces sleep: an in vivo microdialysis study. Sleep 26: 943-947.

Murillo-Rodriguez E, Cabeza R, Mendez-Diaz M, Navarro L, Prospero-Garcia O (2001). Anandamide-induced sleep is blocked by SR141716A, a CB1 receptor antagonist and by U73122, a phospholipase C inhibitor. NeuroReport 12 2131-2136.

Muscatell KA, Dedovic K, Slavich GM, Jarcho MR, Breen EC, Bower JE et al (2015). Greater amygdala activity and dorsomedial prefrontal-amygdala coupling are associated with enhanced inflammatory responses to stress. Brain Behav Immun 43: 46-53.

Naderi N, Haghparast A, Saber-Tehrani A, Rezaii N, Alizadeh AM, Khani A et al (2008). Interaction between cannabinoid compounds and diazepam on anxiety-like behaviour of mice. Pharmacol Biochem Behav 89: 64-75.

Naidu PS, Varvel SA, Ahn K, Cravatt BF, Martin BR, Lichtman AH (2007). Evaluation of fatty acid amide hydrolase inhibition in murine models of emotionality. Psychopharmacology 192: 61-70.

Nakano S, Gillespie HK, Hollister LE (1978). A model for evaluation of antianxiety drugs with the use of experimentally induced stress: comparison of Nabilone and diazepam. Clin Pharmacol Ther 23: 54-62.

Natividad LA, Buczynski MW, Herman MA, Kirson D, Oleata CS, Irimia C et al (2017). Constitutive increases in amygdalar corticotropin-releasing factor and fatty acid amide hydrolase drive an anxious phenotype. Biol Psychiatry (e-pub ahead of print).

Navarro M, Hernandez E, Munoz RM, del Arco I, Villanua MA, Carrera MR et al (1997). Acute administration of the CB1 cannabinoid receptor antagonist SR 141716A induces anxiety-like responses in the rat. NeuroReport 8: 491-496.

Neumeister A, Normandin MD, Pietrzak RH, Piomelli D, Zheng MQ, Gujarro-Anton A et al (2013). Elevated brain cannabinoid CB1 receptor availability in post-traumatic 
stress disorder: a positron emission tomography study. Mol Psychiatry 18: 1034-1040.

Niederhoffer N, Hansen HH, Fernandez-Ruiz JJ, Szabo B (2001). Effects of cannabinoids on adrenaline release from adrenal medullary cells. $\mathrm{Br} \mathrm{J}$ Pharmacol 134: 1319-1327.

Niederhoffer N, Schmid K, Szabo B (2003). The peripheral sympathetic nervous system is the major target of cannabinoids in eliciting cardiovascular depression. Naunyn Schmiedebergs Arch Pharmacol 367: 434-443.

Nievergelt CM, Maihofer AX, Mustapic M, Yurgil KA, Schork NJ, Miller MW et al (2015). Genomic predictors of combat stress vulnerability and resilience in U.S. marines: a genome-wide association study across multiple ancestries implicates PRTFDC1 as a potential PTSD gene. Psychoneuroendocrinology 51: 459-471.

Niyuhire F, Varvel SA, Martin BR, Lichtman AH (2007). Exposure to marijuana smoke impairs memory retrieval in mice. J Pharmacol Exp Ther 322: 1067-1075.

O'Brien LD, Wills KL, Segsworth B, Dashney B, Rock EM, Limebeer CL et al (2013). Effect of chronic exposure to rimonabant and phytocannabinoids on anxiety-like behavior and saccharin palatability. Pharmacol Biochem Behav 103: 597-602.

O'Donovan A, Sun B, Cole S, Rempel H, Lenoci M, Pulliam L et al (2011). Transcriptional control of monocyte gene expression in post-traumatic stress disorder. Dis Markers 30: 123-132.

Orr SP, Metzger LJ, Lasko NB, Macklin ML, Peri T, Pitman RK (2000). De novo conditioning in trauma-exposed individuals with and without posttraumatic stress disorder. J Abnorm Psychol 109: 290-298.

Palazuelos J, Davoust N, Julien B, Hatterer E, Aguado T, Mechoulam R et al (2008). The $\mathrm{CB}(2)$ cannabinoid receptor controls myeloid progenitor trafficking: involvement in the pathogenesis of an animal model of multiple sclerosis. J Biol Chem 283: $13320-13329$

Pamplona FA, Bitencourt RM, Takahashi RN (2008). Short- and long-term effects of cannabinoids on the extinction of contextual fear memory in rats. Neurobiol Learn Mem 90: 290-293.

Pamplona FA, Takahashi RN (2006). WIN 55212-2 impairs contextual fear conditioning through the activation of CB1 cannabinoid receptors. Neurosci Lett 397: 88-92.

Papini S, Ruglass LM, Lopez-Castro T, Powers MB, Smits JA, Hien DA (2017). Chronic cannabis use is associated with impaired fear extinction in humans. J Abnorm Psychol 126: 117-124.

Patel S, Hill MN, Cheer J, Wotjak CT, Holmes A (2017). The endocannabinoid system as a target for novel anxiolytic drugs. Neurosci Biobehav Rev 76: 56-66.

Patel S, Hillard CJ (2006). Pharmacological evaluation of cannabinoid receptor ligands in a mouse model of anxiety: further evidence for an anxiolytic role for endogenous cannabinoid signaling. J Pharmacol Exp Ther 318: 304-311.

Patel S, Roelke CT, Rademacher DJ, Cullinan WE, Hillard CJ (2004). Endocannabinoid signaling negatively modulates stress-induced activation of the hypothalamic-pituitary-adrenal axis. Endocrinology 145: 5431-5438.

Patel S, Roelke CT, Rademacher DJ, Hillard CJ (2005). Inhibition of restraint stressinduced neural and behavioural activation by endogenous cannabinoid signalling. Eur J Neurosci 21: 1057-1069.

Pava MJ, den Hartog CR, Blanco-Centurion C, Shiromani PJ, Woodward JJ (2014). Endocannabinoid modulation of cortical up-states and NREM sleep. PLOS ONE 9: e88672.

Pava MJ, Makriyannis A, Lovinger DM (2016). Endocannabinoid signaling regulates sleep stability. PLOS ONE 11: e0152473.

Perkonigg A, Kessler RC, Storz S, Wittchen HU (2000). Traumatic events and post-traumatic stress disorder in the community: prevalence, risk factors and comorbidity. Acta Psychiatr Scand 101: 46-59.

Perra S, Pillolla G, Luchicchi A, Pistis M (2008). Alcohol inhibits spontaneous activity of basolateral amygdala projection neurons in the rat: involvement of the endocannabinoid system. Alcohol Clin Exp Res 32: 443-449.

Pertwee RG (1974). Tolerance to the effect of delta1-tetrahydrocannabinol on corticosterone levels in mouse plasma produced by repeated administration of cannabis extract or delta1-tetrahydrocannabinol. Br J Pharmacol 51: 391-397.

Phan KL, Angstadt M, Golden J, Onyewuenyi I, Popovska A, de Wit H (2008). Cannabinoid modulation of amygdala reactivity to social signals of threat in humans. J Neurosci 28: 2313-2319.

Pickens CL, Theberge FR (2014). Blockade of CB1 receptors prevents retention of extinction but does not increase low preincubated conditioned fear in the fear incubation procedure. Behav Pharmacol 25: 23-31.

Piri M, Zarrindast MR (2011). Modulation of WIN55,212-2 state-dependent memory by alpha2-adrenergic receptors of the dorsal hippocampus. Arch Iran Med 14: 389-395.

Pistis M, Ferraro L, Pira L, Flore G, Tanganelli S, Gessa GL et al (2002). Delta(9)tetrahydrocannabinol decreases extracellular GABA and increases extracellular glutamate and dopamine levels in the rat prefrontal cortex: an in vivo microdialysis study. Brain Res 948: 155-158.
Pistis M, Perra S, Pillolla G, Melis M, Gessa GL, Muntoni AL (2004). Cannabinoids modulate neuronal firing in the rat basolateral amygdala: evidence for CB1- and non-CB1-mediated actions. Neuropharmacology 46: 115-125.

Pitman RK, Rasmusson AM, Koenen KC, Shin LM, Orr SP, Gilbertson MW et al (2012). Biological studies of post-traumatic stress disorder. Nat Rev Neurosci 13: 769-787.

Powell DR, Gay JP, Wilganowski N, Doree D, Savelieva KV, Lanthorn TH et al (2015). Diacylglycerol lipase alpha knockout mice demonstrate metabolic and behavioral phenotypes similar to those of cannabinoid receptor 1 knockout mice. Front Endocrinol 6: 86.

Prager G, Hadamitzky M, Engler A, Doenlen R, Wirth T, Pacheco-Lopez G et al (2013). Amygdaloid signature of peripheral immune activation by bacterial lipopolysaccharide or staphylococcal enterotoxin B. J Neuroimmune Pharmacol 8: $42-50$.

Prospero-Garcia O, Amancio-Belmont O, Becerril Melendez AL, Ruiz-Contreras AE, Mendez-Diaz M (2016). Endocannabinoids and sleep. Neurosci Biobehav Rev 71 : 671-679.

Puder M, Weidenfeld J, Chowers I, Nir I, Conforti N, Siegel RA (1982). Corticotrophin and corticosterone secretion following delta 1-tetrahydrocannabinol, in intact and in hypothalamic deafferentated male rats. Exp Brain Res 46: 85-88.

Qin Z, Zhou X, Pandey NR, Vecchiarelli HA, Stewart CA, Zhang X et al (2015). Chronic stress induces anxiety via an amygdalar intracellular cascade that impairs endocannabinoid signaling. Neuron 85: 1319-1331.

Rabinak CA, Angstadt M, Lyons M, Mori S, Milad MR, Liberzon I et al (2014). Cannabinoid modulation of prefrontal-limbic activation during fear extinction learning and recall in humans. Neurobiol Learn Mem 113: 125-134.

Rabinak CA, Angstadt M, Sripada CS, Abelson JL, Liberzon I, Milad MR et al (2013). Cannabinoid facilitation of fear extinction memory recall in humans. Neuropharmacology 64: 396-402.

Rademacher DJ, Meier SE, Shi L, Ho WS, Jarrahian A, Hillard CJ (2008). Effects of acute and repeated restraint stress on endocannabinoid content in the amygdala, ventral striatum, and medial prefrontal cortex in mice. Neuropharmacology 54: 108-116.

Ramikie TS, Nyilas R, Bluett RJ, Gamble-George JC, Hartley ND, Mackie K et al (2014). Multiple mechanistically distinct modes of endocannabinoid mobilization at central amygdala glutamatergic synapses. Neuron 81: 1111-1125.

Ramikie TS, Patel S (2012). Endocannabinoid signaling in the amygdala: anatomy, synaptic signaling, behavior, and adaptations to stress. Neuroscience 204: 38-52.

Reich CG, Mohammadi MH, Alger BE (2008). Endocannabinoid modulation of fear responses: learning and statedependent performance effects. J Psychopharmacol 22: 769-777.

Reilly D, Didcott P, Swift W, Hall W (1998). Long-term cannabis use: characteristics of users in an Australian rural area. Addiction 93: 837-846.

Rey AA, Purrio M, Viveros MP, Lutz B (2012). Biphasic effects of cannabinoids in anxiety responses: $\mathrm{CB} 1$ and $\mathrm{GABA}(\mathrm{B})$ receptors in the balance of GABAergic and glutamatergic neurotransmission. Neuropsychopharmacology 37: 2624-2634.

Roberts CJ, Stuhr KL, Hutz MJ, Raff H, Hillard CJ (2014). Endocannabinoid signaling in hypothalamic-pituitary-adrenocortical axis recovery following stress: effects of indirect agonists and comparison of male and female mice. Pharmacol Biochem Behav 117: 17-24.

Roche M, Kelly JP, O'Driscoll M, Finn DP (2008). Augmentation of endogenous cannabinoid tone modulates lipopolysaccharide-induced alterations in circulating cytokine levels in rats. Immunology 125: 263-271.

Rock EM, Bolognini D, Limebeer CL, Cascio MG, Anavi-Goffer S, Fletcher PJ et al (2012). Cannabidiol, a non-psychotropic component of cannabis, attenuates vomiting and nausea-like behaviour via indirect agonism of 5-HT(1A) somatodendritic autoreceptors in the dorsal raphe nucleus. Br J Pharmacol 165: 2620-2634.

Rodgers RJ, Evans PM, Murphy A (2005). Anxiogenic profile of AM-251, a selective cannabinoid $\mathrm{CB} 1$ receptor antagonist, in plus-maze-naive and plus-mazeexperienced mice. Behav Pharmacol 16: 405-413.

Rodgers RJ, Haller J, Halasz J, Mikics E (2003). 'One-trial sensitization' to the anxiolytic-like effects of cannabinoid receptor antagonist SR141716A in the mouse elevated plus-maze. Eur J Neurosci 17: 1279-1286.

Rodriguez de Fonseca FR, Villanua MA, Munoz RM, San-Martin-Clark O, Navarro M (1995). Differential effects of chronic treatment with either dopamine D1 or D2 receptor agonists on the acute neuroendocrine actions of the highly potent synthetic cannabinoid HU-210 in male rats. Neuroendocrinology 61: 714-721.

Roitman P, Mechoulam R, Cooper-Kazaz R, Shalev A (2014). Preliminary, open-label, pilot study of add-on oral Delta9-tetrahydrocannabinol in chronic post-traumatic stress disorder. Clin Drug Investig 34: 587-591.

Rom S, Persidsky Y (2013). Cannabinoid receptor 2: potential role in immunomodulation and neuroinflammation. J Neuroimmune Pharmacol 8: 608-620. 
Romero EM, Fernandez B, Sagredo O, Gomez N, Uriguen L, Guaza C et al (2002). Antinociceptive, behavioural and neuroendocrine effects of CP 55,940 in young rats. Brain Res Dev Brain Res 136: 85-92.

Ross DA, Arbuckle MR, Travis MJ, Dwyer JB, van Schalkwyk Gl, Ressler KJ (2017). An integrated neuroscience perspective on formulation and treatment planning for posttraumatic stress disorder: an educational review. JAMA Psychiatry 74: 407-415.

Ross RJ, Ball WA, Dinges DF, Kribbs NB, Morrison AR, Silver SM et al (1994). Rapid eye movement sleep disturbance in posttraumatic stress disorder. Biol Psychiatry 35: 195-202.

Ross RJ, Ball WA, Sullivan KA, Caroff SN (1989). Sleep disturbance as the hallmark of posttraumatic stress disorder. Am J Psychiatry 146: 697-707.

Rossi S, De Chiara V, Musella A, Sacchetti L, Cantarella C, Castelli M et al (2010). Preservation of striatal cannabinoid CB1 receptor function correlates with the antianxiety effects of fatty acid amide hydrolase inhibition. Mol Pharmacol 78: 260-268.

Rossignoli MT, Lopes-Aguiar C, Ruggiero RN, Do Val da Silva RA, Bueno-Junior LS, Kandratavicius $L$ et al (2017). Selective post-training time window for memory consolidation interference of cannabidiol into the prefrontal cortex: reduced dopaminergic modulation and immediate gene expression in limbic circuits. Neuroscience 350: 85-93.

Rubino T, Realini N, Castiglioni C, Guidali C, Vigano D, Marras E et al (2008). Role in anxiety behavior of the endocannabinoid system in the prefrontal cortex. Cereb Cortex 18: 1292-1301.

Rubino T, Sala M, Vigano D, Braida D, Castiglioni C, Limonta V et al (2007). Cellular mechanisms underlying the anxiolytic effect of low doses of peripheral Delta9tetrahydrocannabinol in rats. Neuropsychopharmacology 32: 2036-2045.

Ruehle S, Remmers F, Romo-Parra H, Massa F, Wickert M, Wortge S et al (2013). Cannabinoid CB1 receptor in dorsal telencephalic glutamatergic neurons: distinctive sufficiency for hippocampus-dependent and amygdala-dependent synaptic and behavioral functions. J Neurosci 33: 10264-10277.

Sanchis-Segura C, Cline BH, Marsicano G, Lutz B, Spanagel R (2004). Reduced sensitivity to reward in CB1 knockout mice. Psychopharmacology 176: 223-232.

Sano K, Koushi E, Irie K, Higuchi S, Tsuchihashi R, Kinjo J et al (2009). Delta(9)tetrahydrocannabinol enhances an increase of plasma corticosterone levels induced by forced swim-stress. Biol Pharm Bull 32: 2065-2067.

Santucci V, Storme JJ, Soubrie P, Le Fur G (1996). Arousal-enhancing properties of the CB1 cannabinoid receptor antagonist SR 141716A in rats as assessed by electroencephalographic spectral and sleep-waking cycle analysis. Life Sci 58: PL103-PL110.

Sardinha J, Kelly ME, Zhou J, Lehmann C (2014). Experimental cannabinoid 2 receptor-mediated immune modulation in sepsis. Mediators Inflamm 2014: 978678.

Scherma M, Medalie J, Fratta W, Vadivel SK, Makriyannis A, Piomelli D et al (2008). The endogenous cannabinoid anandamide has effects on motivation and anxiety that are revealed by fatty acid amide hydrolase (FAAH) inhibition. Neuropharmacology 54: 129-140.

Schlosburg JE, Blankman JL, Long JZ, Nomura DK, Pan B, Kinsey SG et al (2010). Chronic monoacylglycerol lipase blockade causes functional antagonism of the endocannabinoid system. Nat Neurosci 13: 1113-1119.

Sciolino NR, Zhou W, Hohmann AG (2011). Enhancement of endocannabinoid signaling with JZL184, an inhibitor of the 2-arachidonoylglycerol hydrolyzing enzyme monoacylglycerol lipase, produces anxiolytic effects under conditions of high environmental aversiveness in rats. Pharmacol Res 64: 226-234.

Segev A, Akirav I (2011). Differential effects of cannabinoid receptor agonist on social discrimination and contextual fear in amygdala and hippocampus. Learn Mem 18: 254-259.

Sexton M, Cudaback E, Abdullah RA, Finnell J, Mischley LK, Rozga M et al (2014). Cannabis use by individuals with multiple sclerosis: effects on specific immune parameters. Inflammopharmacology 22: 295-303.

Sheynin J, Liberzon I (2016). Circuit dysregulation and circuit-based treatments in posttraumatic stress disorder. Neurosci Lett 649: 133-138.

Shimizu T, Lu L, Yokotani K (2010). Possible inhibitory roles of endogenous 2-arachidonoylglycerol during corticotropin-releasing factor-induced activation of central sympatho-adrenomedullary outflow in anesthetized rats. Eur J Pharmacol 641: 54-60.

Shin LM, Orr SP, Carson MA, Rauch SL, Macklin ML, Lasko NB et al (2004). Regional cerebral blood flow in the amygdala and medial prefrontal cortex during traumatic imagery in male and female Vietnam veterans with PTSD. Arch Gen Psychiatry 61: 168-176.

Shin LM, Rauch SL, Pitman RK (2006). Amygdala, medial prefrontal cortex, and hippocampal function in PTSD. Ann NY Acad Sci 1071: 67-79.

Shonesy BC, Bluett RJ, Ramikie TS, Baldi R, Hermanson DJ, Kingsley PJ et al (2014). Genetic disruption of 2-arachidonoylglycerol synthesis reveals a key role for endocannabinoid signaling in anxiety modulation. Cell Rep 9: 1644-1653.
Silvani A, Berteotti C, Bastianini S, Lo Martire V, Mazza R, Pagotto U et al (2014). Multiple sleep alterations in mice lacking cannabinoid type 1 receptors. PLOS ONE 9: e89432.

Simkins T, Crawford RB, Goudreau JL, Lookingland KJ, Kaplan BL (2014). Enhanced humoral immunity in mice lacking CB1 and CB2 receptors (Cnr1 - / $-/$ Cnr2-/- mice) is not due to increased splenic noradrenergic neuronal activity. J Neuroimmune Pharmacol 9: 544-557.

Simone JJ, Malivoire BL, McCormick CM (2015). Effects of CB1 receptor agonism and antagonism on behavioral fear and physiological stress responses in adult intact, ovariectomized, and estradiol-replaced female rats. Neuroscience 306: 123-137.

Singareddy RK, Balon R (2002). Sleep in posttraumatic stress disorder. Ann Clin Psychiatry 14: 183-190.

Sink KS, Segovia KN, Sink J, Randall PA, Collins LE, Correa M et al (2010). Potential anxiogenic effects of cannabinoid CB1 receptor antagonists/inverse agonists in rats: comparisons between AM4113, AM251, and the benzodiazepine inverse agonist FG-7142. Eur Neuropsychopharmacol 20: 112-122.

Sipe JC, Chiang K, Gerber AL, Beutler E, Cravatt BF (2002). A missense mutation in human fatty acid amide hydrolase associated with problem drug use. Proc Natl Acad Sci USA 99: 8394-8399.

Spagnolo PA, Ramchandani VA, Schwandt ML, Kwako LE, George DT, Mayo LM et al (2016). FAAH gene variation moderates stress response and symptom severity in patients with posttraumatic stress disorder and comorbid alcohol dependence. Alcohol Clin Exp Res 40: 2426-2434.

Spoont MR, Murdoch M, Hodges J, Nugent S (2010). Treatment receipt by veterans after a PTSD diagnosis in PTSD, mental health, or general medical clinics. Psychiatr Serv 61: 58-63.

Steenkamp MM, Blessing EM, Galatzer-Levy IR, Hollahan LC, Anderson WT (2017). Marijuana and other cannabinoids as a treatment for posttraumatic stress disorder: a literature review. Depress Anxiety 34: 207-216.

Stern CA, Gazarini L, Vanvossen AC, Zuardi AW, Galve-Roperh I, Guimaraes FS et al (2015). Delta9-tetrahydrocannabinol alone and combined with cannabidiol mitigate fear memory through reconsolidation disruption. Eur Neuropsychopharmacol 25: 958-965.

Storr MA, Keenan CM, Emmerdinger D, Zhang H, Yuce B, Sibaev A et al (2008). Targeting endocannabinoid degradation protects against experimental colitis in mice: involvement of CB1 and CB2 receptors. J Mol Med 86: 925-936.

Storr MA, Keenan CM, Zhang H, Patel KD, Makriyannis A, Sharkey KA (2009). Activation of the cannabinoid 2 receptor (CB2) protects against experimental colitis. Inflamm Bowel Dis 15: 1678-1685.

Sugiura T, Kondo S, Sukagawa A, Nakane S, Shinoda A, Itoh K et al (1995). 2-arachidonoylglycerol: a possible endogenous cannabinoid receptor ligand in brain. Biochem Biophys Res Commun 215: 89-97.

Sumislawski JJ, Ramikie TS, Patel S (2011). Reversible gating of endocannabinoid plasticity in the amygdala by chronic stress: a potential role for monoacylglycerol lipase inhibition in the prevention of stress-induced behavioral adaptation. Neuropsychopharmacology 36: 2750-2761.

Suzuki A, Josselyn SA, Frankland PW, Masushige S, Silva AJ, Kida S (2004). Memory reconsolidation and extinction have distinct temporal and biochemical signatures. J Neurosci 24: 4787-4795.

Swartz JR, Prather AA, Hariri AR (2017). Threat-related amygdala activity is associated with peripheral CRP concentrations in men but not women. Psychoneuroendocrinology 78: 93-96.

Tan H, Ahmad T, Loureiro M, Zunder J, Laviolette SR (2014). The role of cannabinoid transmission in emotional memory formation: implications for addiction and schizophrenia. Front Psychiatry 5: 73

Tan H, Lauzon NM, Bishop SF, Bechard MA, Laviolette SR (2010). Integrated cannabinoid $\mathrm{CB} 1$ receptor transmission within the amygdala-prefrontal cortical pathway modulates neuronal plasticity and emotional memory encoding. Cereb Cortex 20: 1486-1496.

Tawakol A, Ishai A, Takx RA, Figueroa AL, Ali A, Kaiser Y et al (2017). Relation between resting amygdalar activity and cardiovascular events: a longitudinal and cohort study. Lancet 389: 834-845.

Tchantchou F, Tucker LB, Fu AH, Bluett RJ, McCabe JT, Patel S et al (2014). The fatty acid amide hydrolase inhibitor PF-3845 promotes neuronal survival, attenuates inflammation and improves functional recovery in mice with traumatic brain injury. Neuropharmacology 85: 427-439.

Temple EC, Driver M, Brown RF (2014). Cannabis use and anxiety: is stress the missing piece of the puzzle? Front Psychiatry 5: 168.

Tham CS, Whitaker J, Luo L, Webb M (2007). Inhibition of microglial fatty acid amide hydrolase modulates LPS stimulated release of inflammatory mediators. FEBS Lett 581: 2899-2904.

Thiemann G, Watt CA, Ledent C, Molleman A, Hasenohrl RU (2009). Modulation of anxiety by acute blockade and genetic deletion of the $\mathrm{CB}(1)$ cannabinoid receptor 
in mice together with biogenic amine changes in the forebrain. Behav Brain Res 200: 60-67.

Turcotte C, Blanchet MR, Laviolette M, Flamand N (2016). The CB2 receptor and its role as a regulator of inflammation. Cell Mol Life Sci 73: 4449-4470.

Van Dam NT, Bedi G, Earleywine M (2012). Characteristics of clinically anxious versus non-anxious regular, heavy marijuana users. Addict Behav 37: 1217-1223.

Varvel SA, Anum EA, Lichtman AH (2005). Disruption of $\mathrm{CB}(1)$ receptor signaling impairs extinction of spatial memory in mice. Psychopharmacology 179: 863-872.

Varvel SA, Wise LE, Niyuhire F, Cravatt BF, Lichtman AH (2007). Inhibition of fatty-acid amide hydrolase accelerates acquisition and extinction rates in a spatial memory task. Neuropsychopharmacology 32: 1032-1041.

Vizi ES, Katona I, Freund TF (2001). Evidence for presynaptic cannabinoid CB(1) receptor-mediated inhibition of noradrenaline release in the guinea pig lung. Eur $J$ Pharmacol 431: 237-244.

Wamsteeker JI, Kuzmiski JB, Bains JS (2010). Repeated stress impairs endocannabinoid signaling in the paraventricular nucleus of the hypothalamus. J Neurosci 30: 11188-11196.

Wang M, Hill MN, Zhang L, Gorzalka BB, Hillard CJ, Alger BE (2012). Acute restraint stress enhances hippocampal endocannabinoid function via glucocorticoid receptor activation. J Psychopharmacol 26: 56-70.

Watts BV, Shiner B, Zubkoff L, Carpenter-Song E, Ronconi JM, Coldwell CM (2014). Implementation of evidence-based psychotherapies for posttraumatic stress disorder in VA specialty clinics. Psychiatr Serv 65: 648-653.

Wedzony K, Chocyk A (2009). Cannabinoid CB1 receptors in rat medial prefrontal cortex are colocalized with calbindin- but not parvalbumin- and calretinin-positive GABA-ergic neurons. Pharmacol Rep 61: 1000-1007.

Weiss A, Friedenberg $F$ (2015). Patterns of cannabis use in patients with inflammatory bowel disease: a population based analysis. Drug Alcohol Depend 156: 84-89.

Wen J, Ribeiro R, Tanaka M, Zhang Y (2015). Activation of CB2 receptor is required for the therapeutic effect of ABHD6 inhibition in experimental autoimmune encephalomyelitis. Neuropharmacology 99: 196-209.

Whitaker AM, Farooq MA, Edwards S, Gilpin NW (2016). Post-traumatic stress avoidance is attenuated by corticosterone and associated with brain levels of steroid receptor co-activator-1 in rats. Stress 19: 69-77.

Whitaker AM, Gilpin NW (2015). Blunted hypothalamo-pituitary adrenal axis response to predator odor predicts high stress reactivity. Physiol Behav 147: 16-22.

Wicking M, Steiger F, Nees F, Diener SJ, Grimm O, Ruttorf M et al (2016). Deficient fear extinction memory in posttraumatic stress disorder. Neurobiol Learn Mem 136: 116-126.

Wieck A, Grassi-Oliveira R, Hartmann do Prado C, Teixeira AL, Bauer ME (2014). Neuroimmunoendocrine interactions in post-traumatic stress disorder: focus on long-term implications of childhood maltreatment. Neuroimmunomodulation 21: 145-151.

Wilkinson ST, Radhakrishnan R, D'Souza DC (2016). A systematic review of the evidence for medical marijuana in psychiatric indications. J Clin Psychiatry 77: 1050-1064.
Willoughby KA, Moore SF, Martin BR, Ellis EF (1997). The biodisposition and metabolism of anandamide in mice. J Pharmacol Exp Ther 282: 243-247.

Yamada D, Takeo J, Koppensteiner P, Wada K, Sekiguchi M (2014). Modulation of fear memory by dietary polyunsaturated fatty acids via cannabinoid receptors. Neuropsychopharmacology 39: 1852-1860.

Yang YL, Chao PK, Lu KT (2006). Systemic and intra-amygdala administration of glucocorticoid agonist and antagonist modulate extinction of conditioned fear. Neuropsychopharmacology 31: 912-924.

Yang YL, Chao PK, Ro LS, Wo YY, Lu KT (2007). Glutamate NMDA receptors within the amygdala participate in the modulatory effect of glucocorticoids on extinction of conditioned fear in rats. Neuropsychopharmacology 32: 1042-1051.

Yehuda R (2009). Status of glucocorticoid alterations in post-traumatic stress disorder. Ann NY Acad Sci 1179: 56-69.

Yehuda R, Bierer LM, Pratchett LC, Lehrner A, Koch EC, Van Manen JA et al (2015a). Cortisol augmentation of a psychological treatment for warfighters with posttraumatic stress disorder: randomized trial showing improved treatment retention and outcome. Psychoneuroendocrinology 51: 589-597.

Yehuda R, Cai G, Golier JA, Sarapas C, Galea S, Ising M et al (2009). Gene expression patterns associated with posttraumatic stress disorder following exposure to the World Trade Center attacks. Biol Psychiatry 66: 708-711.

Yehuda R, Hoge CW, McFarlane AC, Vermetten E, Lanius RA, Nievergelt CM et al (2015b). Post-traumatic stress disorder. Nat Rev Dis Primers 1: 15057.

Yehuda R, Teicher MH, Trestman RL, Levengood RA, Siever LJ (1996). Cortisol regulation in posttraumatic stress disorder and major depression: a chronobiological analysis. Biol Psychiatry 40: 79-88.

Yu Z, Fukushima H, Ono C, Sakai M, Kasahara Y, Kikuchi Y et al (2017). Microglial production of TNF-alpha is a key element of sustained fear memory. Brain Behav Immun 59: 313-321.

Zarrindast MR, Navaeian M, Nasehi M (2011). Influence of three-day morphinetreatment upon impairment of memory consolidation induced by cannabinoid infused into the dorsal hippocampus in rats. Neurosci Res 69: 51-59.

Zhong P, Wang W, Pan B, Liu X, Zhang Z, Long JZ et al (2014). Monoacylglycerol lipase inhibition blocks chronic stress-induced depressive-like behaviors via activation of mTOR signaling. Neuropsychopharmacology 39: 1763-1776.

Zhu PJ, Lovinger DM (2005). Retrograde endocannabinoid signaling in a postsynaptic neuron/synaptic bouton preparation from basolateral amygdala. J Neurosci 25: 6199-6207.

Zohar J, Yahalom H, Kozlovsky N, Cwikel-Hamzany S, Matar MA, Kaplan Z et al (2011). High dose hydrocortisone immediately after trauma may alter the trajectory of PTSD: interplay between clinical and animal studies. Eur Neuropsychopharmacol 21: 796-809.

Zoppi S, Madrigal JL, Caso JR, Garcia-Gutierrez MS, Manzanares J, Leza JC et al (2014). Regulatory role of the cannabinoid CB2 receptor in stress-induced neuroinflammation in mice. Br J Pharmacol 171: 2814-2826.

Zuardi AW, Teixeira NA, Karniol IC (1984). Pharmacological interaction of the effects of delta 9-trans-tetrahydrocannabinol and cannabidiol on serum corticosterone levels in rats. Arch Int Pharmacodyn Ther 269: 12-19. 